\title{
Heterogeneity in the Adoption of Photovoltaic Systems in Flanders
}

\author{
Olivier De Groote* Guido Pepermans* $\quad$ Frank Verboven*
}

March 2016

\begin{abstract}
We study the determinants of PV adoption in the region of Flanders (Belgium), where PV adoption reached high levels during 2006-2012, because of active government intervention. Based on a unique dataset at a very detailed spatial level, we estimate a Poisson model to explain the heterogeneity in adoption rates. We obtain the following findings. First, local policies have a robust and significant impact on PV adoption. Second, there is a strong unconditional income effect, implying a Matthew effect in the subsidization of PVs. Our third finding is however that this income effect is largely driven by the fact that wealthier households are more likely to adopt because they tend to be higher users, are more frequent house owners, or own houses that are better suited for PV. In several extensions, we consider the determinants of the average size of installed PVs, and the differential impact of certain variables over time.
\end{abstract}

Keywords: Adoption of photovoltaic systems; renewable energy sources; Poisson regression

JEL-classification:

Corresponding Address:

Guido Pepermans

KU Leuven, Campus Brussels

Faculty of Economics and Business

Warmoesberg 26

B-1000 Brussels

Belgium

e-mail: guido.pepermans@kuleuven.be

* $\quad$ 0. De Groote: KU Leuven, Campus Leuven, Faculty of Economics and Business and Ph.D. fellow of the Research Foundation Flanders (FWO), olivier.degroote@kuleuven.be.

G. Pepermans: KU Leuven, Campus Brussels, Faculty of Economics and Business, guido.pepermans@kuleuven.be.

F. Verboven: KU Leuven, Campus Leuven, Faculty of Economics and Business and CEPR, frank.verboven@kuleuven.be.

The paper benefited from discussions with the participants of the annual Workshop on Empirical Methods in Energy Economics, held at the University of Maryland, the $2^{\text {nd }}$ BAEE research workshop on Energy Economics, held at KU Leuven, and the $7^{\text {th }}$ BEED workshop, held at Hasselt University. We are especially grateful to two anonymous referees for their helpful comments, 


\section{INTRODUCTION}

Many countries have rolled out policies to stimulate the use of renewables for the production of electricity, the overarching motivation being security of supply and climate change. Within the group of renewable technologies and more specifically solar technologies, photovoltaic panels (PVs) have been among the most stimulated ones, despite their relatively unfavorable cost structure compared to other renewable technologies.

A distinguishing factor of the PV technology is its scalability, i.e. it is a technology that can easily be adopted by small (residential) customers. From a political perspective, this is a favorable characteristic as renewables policies targeting residential PVs have an immediate visibility impact. Over the past decade, many countries worldwide have thus taken policy initiatives to foster the adoption of PVs, for example through tax credits or production subsidies. However, few years later, many of these countries also decided to roll back these initiatives, as they turned out to be much more expensive than initially anticipated, due to too generous subsidy schemes.

Policymakers became increasingly aware of the socioeconomic impact of the large scale adoption of PV through the net metering principle, which means that customers are only charged for the net amount of electricity they use (Cai et al. (2013), Darghouth et al. (2011)). ${ }^{1}$ As infrastructure costs are recovered through a surcharge on the $\mathrm{kWh}$ price, an unanticipated side effect of the net metering principle is that PV customers end up contributing less for these costs than non-PV owners, despite the fact that they also use the grid infrastructure intensively. Moreover, it has been widely shown that higher income customers typically consume more electricity, implying that they have larger incentives to adopt PV enabling them to avoid paying these infrastructure charges. This evolution, the so-called 'death spiral' (Borenstein and Bushnell (2015)), which has been observed in many countries, has induced policy makers to roll back policy initiatives in support of PV.

Generous support policies also made residential PV very popular in Flanders, the largest region of Belgium. Our main purpose is to explain the spatial adoption pattern of PV that emerged, by including a rich set of socioeconomic and housing variables in our empirical model.

The decision to adopt a PV system has recently been studied from different perspectives. While some of these studies use interviews and survey data as their source of information (Jager (2006), Schelly (2014), Vasseur and Kemp (2015), Willis et al. (2011), Faiers and Neame (2006)), most studies use data on all PV installations as the basis for their analysis, possibly limited to a geographical subset of the full database (Bollinger and Gillingham (2012), Crago and Chernyakhovskiy (2014), Davidson et al. (2014), Drury et al. (2012), Kwan (2012), Letchford et al. (2014), Macal et al. (2014), Richter (2013), Robinson et al. (2013), Rode and Weber (2011)). Within this last group of studies, Macal et al. (2014) and Robinson et al. (2013) use agent-based modelling to analyze the PV adoption decision, while all other studies follow an empirical approach in assessing the factors that determine the decision to adopt PV.

A first strand in this empirical literature focuses on whether peer effects are observed in the diffusion process of PV (Bollinger and Gillingham (2012), Letchford et al. (2014), Macal et al. (2014), Richter (2013), Robinson et al. (2013), Rode and Weber (2011)). A second strand of literature focuses on understanding other determinants, in particular the role of state policy incentives (Crago and Chernyakhovskiy (2014)), third-party PV products (Drury et al. (2012) and environmental, economic, social and political factors on PV adoption behavior (Kwan (2012), Davidson et al. (2014)). The latter two papers are the most relevant for our study in terms of type of data and empirical approach. They study the role of geospatial information (such as

\footnotetext{
Net metering allows electricity customers to generate their own electricity in order to offset their consumption of electricity. Typically, this is done through a single bi-directional meter. In times of excess electricity generation, the meter spins backward, while in times of excess electricity demand, the meter spins forward. At the end of the billing period, the customer pays for the net amount of electricity consumed within that period. The practical implementation of the net metering principle can vary widely.
} 
environmental, social, economic and political factors) on the adoption of residential PV across the US and California.

This paper contributes to this second strand of literature in various ways. First, we incorporate a much richer set of socioeconomic characteristics than in previous work, which gives interesting new insights. To illustrate this, we will use the set of covariates used by Kwan (2012) as a benchmark for comparison. Furthermore, we include a set of housing characteristics, which has not been considered in previous work. As such, we explain the underlying reasons for the previously documented fact that PV adoption is more likely when the house value is high. In addition, our data set is at a much finer level of aggregation than previous work. Our unit of observation is the statistical sector, which on average contains only 280 households, much less than the number of households within US zip codes. In contrast with other work, we do not only look at the number of PVs, but also at the size of the installed PVs, and we compare differences between early and late adopters.

Finally, this paper is, to our knowledge, the first study focusing on explaining heterogeneity in the adoption of PV, using the complete installed base of PV in a region outside the US. ${ }^{2}$ The case of Flanders is rather unique in the sense that the average PV adoption in the region was close to 9\%, which is high compared to the countries or regions studied before. To study the determinants of PV adoption, we use a Poisson model with some adjustments to deal with spatial patterns in the data. $^{3}$

The outline of the paper is as follows. Section 2 briefly describes the policy measures in place in Flanders, as they are considered to be a major driver in the adoption of PV. Section 3 describes the data. Section 4 introduces and motivates our empirical approach. Section 5 discusses the empirical results for the determinants of PV adoption, and two extensions (size of installed PVs and the differences between early and late adopters). Finally, section 6 summarizes our main findings and concludes.

\section{POLICY MEASURES TO SUPPORT RESIDENTIAL PV IN FLANDERS}

Because most traditional sources of electricity production involve the depletion of natural resources, governments encourage renewable energy sources (RES) as a more environmentally friendly way of producing electricity. In Belgium, the policy towards RES is largely a competence of the three regions: Flanders, Wallonia and the Brussels Capital Region. Nevertheless, there are also support measures by the Federal Authority and by many of the municipalities. We first discuss the general support measures, and then describe the support measures of the municipalities.

As a general background, the fundamental incentives that drive the decision to invest in PV's are the upfront installation costs and the future benefits from electricity production. The government can influence both components through subsidies or tax cuts. We discuss these now, and in Appendix C we provide some simplified calculations on their relative importance in net present value terms.

\footnotetext{
Richter (2013) and Rode and Weber (2011) also study a non-US region (England and Wales, and Germany) on the basis of the complete installation base, but their focus is on the presence of peer effects.

3 Our Poisson model differs from Kwan (2012), who estimates a zero-inflated negative binomial model on US data and from Davidson et al. (2014), who uses a log-linear specification. We motivate our model in section 4, and report robustness analysis with respected to a zero-inflated negative binomial in the Appendix.
} 


\subsection{General support, applicable to all households 4}

\section{Upfront investment support: subsidy, tax cut and green loans}

In 2002, the regional government of Flanders introduced its first support scheme for PV, which consisted of a subsidy of $65 \%$ of the total investment cost. The program was phased out in 2006 and 2007 with subsidies of $10 \%$ of the investment costs (up to a cap of $7000 € / \mathrm{kWp}$ and a maximum capacity of $3 \mathrm{~kW}$ ).

In 2004, the Belgian federal government also introduced a tax credit of $40 \%$ to individuals undertaking certain renewable energy investments, including PV. This percentage and the maximum allowed tax credit has varied over time, until it was abandoned in 2011.

Finally, between 2009-2011, the government granted an interest-rate subsidy of $1.5 \%$ and a tax reduction of $40 \%$ on the residual interest on loans taken out (up to a ceiling).

\section{Support associated with future green electricity production: net metering and green certificates}

All PV installations with a maximum capacity of $10 \mathrm{~kW}$ are eligible for net-metering, i.e. electricity produced by residential installations is automatically deducted from electricity consumed and excess production is injected into the grid (the so-called backward running kWh-meter). However, in case an installation injects more electricity than it has taken from the grid during a billing period, this amount is not financially reimbursed. The distribution system operators (DSOs) initially provided this service for free, but after numerous recommendations of government agencies and legislative procedures, the DSOs introduced an annual fee of around $100 \mathrm{EUR} / \mathrm{kW}$ of the inverter of the PV in July 2015.

Furthermore, households received public support in the form of Tradable Green Certificates (TGC) for their electricity production. These certificates could be sold to the DSOs at a guaranteed price for a fixed number of years. The TGC program applied to various renewable technologies, but it was particularly generous for PV. It started in 2006 with a guaranteed price of $€ 450$ per MWh for 20 years. Since 2010, the conditions gradually became less favorable for several reasons: the high budgetary costs, the falling prices for PV systems which made adoption profitable at lower subsidies, and the increased installed capacity of alternative renewable energy sources (such as a large biomass installation). Since 2014 the TGC system for PVs was entirely abolished. During the period 2006-2013, the TGC system was a major source of support. Even at the high government's used interest rate of 15\%, the present value of the subsidy for a PV with an average capacity amounted to approximately $€ 10000$ during most of the period (see Appendix C).

\subsection{Local support by municipalities}

Municipalities have also used investment subsidies to promote the deployment of renewables on their territory. The subsidies for PV installations range from $10 \%$ to $25 \%$ of the investment cost, typically capped at a maximum amount of $€ 500$ to $€ 1000$. Since these policies show sufficient variation across municipalities, we will incorporate a measure of these subsidies in our empirical analysis. The obtained data will be discussed in section 3 .

The benefits from local support are considerably less important than those from the public support from green certificates. Even the maximum support of $€ 1000$ in some municipalities is about ten times lower than the subsidies in the form of green certificates. We come back to this when interpreting our empirical results.

Finally, note that, given the financial stimuli provided by federal and local authorities, it is up to the consumer to decide to take advantage of these stimuli to invest in PV (whether it be a

\footnotetext{
4 The website of the International Energy Agency was used to write this overview (http://www.iea.org/policiesandmeasures/renewableenergy/?country=Belgium).
} 
residential consumer, an SME or a larger company). Intermediate companies such as Energy Service Company (ESCOs) play only a minor role in the development of energy efficiency projects in Flanders and are virtually absent in the Flemish residential sector.

\section{THE DATA}

Our empirical analysis is based on three main data sources. The cornerstone of the analysis is a database provided by the Flemish energy regulator, VREG. This database contains all officially registered PVs in Flanders ${ }^{5}$ and is matched with data on the statistical sector where each PV system has been installed. We link the resulting database to two other data sets: a dataset containing information on municipal policy measures, and a dataset with socioeconomic and housing information available at the statistical sector level.

\subsection{Data on residential PV installations in Flanders}

The database from the Flemish energy regulator contains information on the location, size and installation date of all RES systems in Flanders. We remove all non-PV installations and PV installations installed before 2006 (a negligible 722 units), leaving us with 226115 units. Furthermore, since we are interested in residential PV installations, we remove all installations with a capacity larger than $10 \mathrm{~kW}$, resulting in a further small decrease to 220464 installations. ${ }^{6}$ Table 1 shows descriptive statistics on the installed PV units in Flanders at the end of 2012. With 220464 installed PVs on a total of 2.58 million households, the adoption rate amounted to $8.55 \%$.

\begin{tabular}{|c|c|c|c|c|c|c|}
\hline VARIABLES & sum & $N$ & mean & st. dev. & $\min$ & $\max$ \\
\hline Capacity of PV in $\mathrm{kW}^{*}$ & 2077070 & 226115 & 9.19 & 54.1 & 0.003 & 6221 \\
\hline Capacity of PV in $\mathrm{kW}$ if $<10 \mathrm{~kW}^{*}$ & 1057458 & 220464 & 4.80 & 2.13 & 0.003 & 10 \\
\hline Flemish households in 2007 & & 2577058 & & & & \\
\hline
\end{tabular}

*: On 31 December 2012

Table 1: Summary statistics on PV in Flanders.

We match the PV installations to statistical sectors, which are very disaggregate local areas typically a set of streets - grouped by socioeconomic, urban and morphological structural features, governed by the Belgian Statistics Office ADSEI. Flanders consists of 9182 statistical sectors, with an average of 280 households per sector. Based on the installation addresses of the PVs and a precise description of which streets belong to which statistical sector, we can link each PV to a unique statistical sector. This in turn enables us to link the data to socioeconomic information at the level of the statistical sector, and to data on public support measures at the more aggregate municipality level.

Out of the 220464 residential PV installations, only 3634 (or 1.65\%) could not be matched to the correct sector due to unidentifiable errors in the address. As the information in the PV database was imputed by the owners of the PV, the matching of the two databases was prone to spelling mistakes, typos and other kinds of errors. We corrected these as much as possible and consider it is reasonable to assume that the remaining errors do not correlate with relevant variables for

\footnotetext{
5 The oldest officially registered PV system dates from 1997. We focus on the 2006-2012 adoptions only, because we are confident they are all registered in the database. This is because the benefits of the TGC support mechanism could only be reaped if the installation was officially registered..

6 This approach was suggested by the VREG and was also followed by Kwan (2012). The data do not allow to unambiguously distinguish residential from commercial PV installations. However, based on the available information in the database, we estimate the number of commercial PV installations owned by SMEs, larger firms or public entities at about 11.000 units, of which about 4000 units (or 1.8\%) have a size of more than $10 \mathrm{~kW}$ and about 7000 units have a size of at most $10 \mathrm{~kW}$ (about $3 \%$ ). Of the latter units, at least 4200 installations are owned by so-called BVBA's, i.e. (typically small) companies with limited liability, For our period of study, the financial incentives to invest in PV are similar for residential and commercial users, with some minor differences. Commercial users receive an investment tax deduction rather than an income tax deduction. Residential consumers have no financial incentive to invest in PV installations with a size of more than $10 \mathrm{~kW}$, as they cannot sell the surplus of their production over their consumption to the market.
} 
our analysis. These unmatched installations are therefore excluded from the econometric analysis. In a limited number of cases, an observation could not be linked to a unique statistical sector. In those cases, the observation was randomly assigned to one of the (limited) candidate sectors. Figure 1 provides a first impression on the spatial distribution of PV installations in Flanders at the end of 2012.

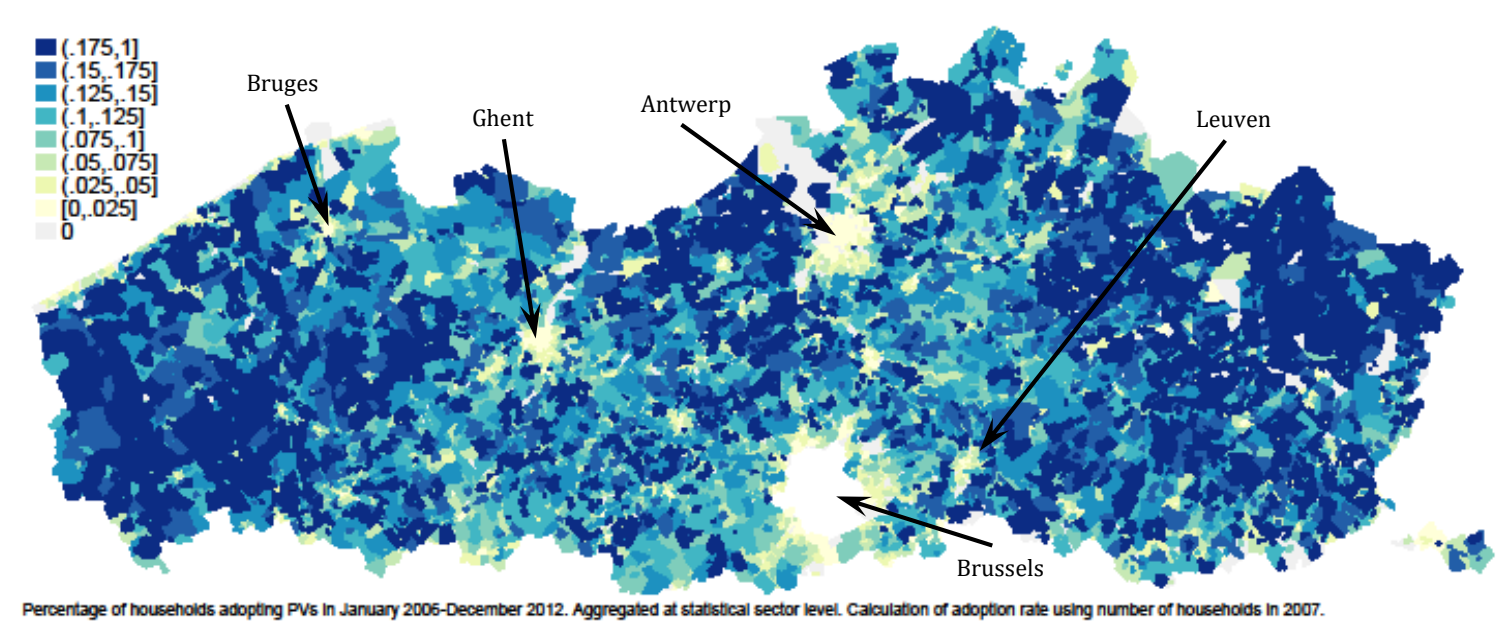

Figure 1: The spatial distribution of PV installations in Flanders

According to Figure 1, more urban areas have a lower density of PV installations, as can be seen from the white or light-shaded spots for Bruges, Ghent, Antwerp, Leuven and the surrounding areas of Brussels. More rural areas such as the northern part of the province of Limburg (east part) and the province of West Flanders (west part) seem to have much higher adoption rates. One possible explanation is that PV installations can potentially capture more sunlight in rural areas, where people are more likely to live in (semi-)detached houses. We will consider these and other possible explanations in our econometric analysis below. Because PV adoption is much lower in urban areas, we will also consider a sensitivity analysis of the main model after excluding these urban areas, and we will show that the results are robust (see Appendix B).

\subsection{Socioeconomic, housing and local support data}

We match the PV database with socioeconomic census data at the level of the statistical sector, available through the SEE2001 census by the Belgian Statistics Office, ADSEI, of which some variables were updated with 2007 data. ${ }^{7}$ Since participation is obligatory and $95 \%$ of the households filled out the questionnaire, we expect that the survey is representative. In addition, we make use of income statement data of the same source (ADSEI). Finally, we obtain additional housing characteristics from the Belgian cadaster and use publically available outcomes of municipality elections. The selection of the variables used in the empirical analysis below was based on the relevant literature.

Table 2 summarizes these variables, and we briefly describe them in the following paragraphs.

\section{SEE2001 census $^{8}$}

A first variable is the number of households. This is used to calculate adoption rates and we expect the number of PVs to move proportionally with the number of households. A second variable is household age, defined by the age of the household's reference person who is mostly

\footnotetext{
7 Algemene Sociaal-Economische Enquête 2001 (http://statbel.fgov.be/nl/statistieken/gegevensinzameling/volkstelling/2001/).

8 For some of the variables we have more recent data than from the 2001 census. We use 2007 data for number of households, population density, household age, household size, gender and ethnicity.
} 
in charge of important decisions. Studies on PV adoption have shown that older people are less likely to adopt (Bollinger and Gillingham (2012), Kwan (2012), Willis et al. (2011)) and some also show a negative effect for younger people. Some studies also show effects related to ethnicity, with whites being more likely to adopt (Bollinger and Gillingham (2012), Kwan (2012)). We expect similar results when using nationality as an explanatory variable (as foreigners are much more likely to be non-whites). Furthermore, we include gender as some studies found that males are more likely to adopt new technologies (e.g. Bollinger and Gillingham (2012)). Information costs are also considered important in the decision to adopt, especially in case of a new technology. We therefore include the level of education, for which Kwan (2012) found a positive effect. Note that next to the information benefits, the level of education is also positively correlated with environmental preferences (Mills and Schleich (2009), Hersch and Viscusi (2006)) or it could be seen as a proxy for lifetime wealth (Hersch and Viscusi (2006)). A variable with a similar interpretation is the occupational status or sector of employment. Kontogianni et al. (2013) found that people working in the public sector are more likely to adopt PV rather than other RES technologies. Household size can also play a role, as larger households have a higher electricity consumption and can share the fixed investment cost among a larger group of beneficiaries (Mills and Schleich (2009)). Population density is included as an explanatory factor, as we can expect that the amount of open space raises the possibility to capture sunlight, which should have a positive impact on the number of PV installations. Kwan (2012) uses a similar measure by taking housing density into account. The presence of a principal-agent problem in the renting market prevents a correct allocation of the investment cost of a PV installation among tenant and landlord. To investigate this, we include house ownership status, defined as the proportion of owner-occupied houses. Crago and Chernyakhovskiy (2014) and Mills and Schleich (2009) found evidence for the presence of a principal-agent problem.

What makes our study different from Kwan (2012) is that we also include variables that capture housing characteristics. The SEE2001 survey contains some interesting variables to investigate these effects, like double glazing and roof insulation and quality of the roof. In the latter case we expect roof quality to be positively correlated with PV installations, as low roof condition involves extra investment costs resulting in lower adoption.

We also try to capture a household's environmental awareness. For this, we use a proxy based on the answer given on the question 'Does your house have roof insulation?'. The proportion of people that were able to answer this question is assumed to reflect how people care about energy efficiency. This is similar to the approach taken by Mills and Schleich (2009) in their study on the adoption of solar thermal installations, where they include data on people's awareness of the energy class of their washing machine. Mills and Schleich (2009) did not find any significant impact.

\section{Cadaster data}

Housing characteristics come from the Belgian cadaster in 2011. The added variables are the house type, house size (measured by built area), house age and the house value (measured by its cadastral income). House age and value are studied by Davidson et al. (2014), They find that both variables are important in explaining adoption, as well as number of rooms in the houses (which probably correlates a lot with our house size variable).

\section{Income data}

We have annual income data at the statistical sector level. For privacy reasons average and median income are only published if there are at least 20 households in the statistical sector. Since 2007, average income is only published if there are at least 200 households. Because average income would be missing for 3500 observations in 2007 or later, we decided to use the 2006 data to construct our income variables.

We use average income per household rather than per tax declaration, because members in the same household may fill out multiple tax declarations. We also have information on the 
dispersion of income per tax declaration in a statistical sector (since the available information does not allow us to calculate this per household. More specifically, we include the interquartile coefficient of income per tax declaration, i.e. the difference between the third and first quartile, divided by the median income per tax declaration. This measure allows one to draw conclusions on the effect of high incomes that cannot be seen by using average household income. ${ }^{9}$

We expect income to influence the adoption process for at least two reasons. First, a lucrative investment can be difficult or impossible due to liquidity constraints (Mills and Schleich (2009)). Second, investing in PV can be considered as a revelation of environmental preferences and such kinds of goods usually are considered luxury goods (Fransson and Gärling (1999)). Thus, demand may increase more than proportionally with income. For PV, Kwan (2012) finds a positive income effect for annual incomes between 25,000 and 100,000 dollars. On the other hand, based on stated preference data, Willis et al. (2011) find a negative income effect for most RES technologies, including PV.

\section{Election results}

We also use data on voting behavior, more precisely the average percentage of votes for leftwing parties (green and socialist parties) in the municipal elections of 2000 and 2006.10 In Flanders, the green and socialist party have largely overlapping views on environmental issues. ${ }^{11} \mathrm{We}$ therefore decided to take the aggregate percentage of green and socialist votes as an indicator of environmental preferences. It should be noted, however, that the green party only participated in 110 out of the 308 municipalities in these elections. When the party did not participate, the number of votes was set equal to zero.

Controlling for environmental preferences is common in the literature. Typically, authors use proxies like the possession of hybrid vehicles (Bollinger and Gillingham (2012), Crago and Chernyakhovskiy (2014)), votes for green ballot initiatives (Kahn and Vaughn (2009)), votes for left parties or membership of certain green organizations (Kwan (2012), Kahn and Vaughn (2009)). Positive effects are found for most of these proxies. A similar conclusion is found by Jager (2006), based on survey data.

\section{Data on local support policies for residential PV}

Finally, we use data on local support schemes from a website maintained by the VEA (Flemish Energy Agency). We recovered information on the availability and magnitude of support mechanisms at a municipality level at three dates: 21 April 2011, 22 June 2011 and 3 July 2012. Since our empirical analysis is cross-sectional, we use the information for April 2011. This is most representative, as it falls in the middle of the period over which PV adoption occurred in our sample. Only 123 of the 308 municipalities (or about 40\%) provide financial support, either in the form of a capped variable subsidy (a percentage of the investment cost) or as a lump sum subsidy. Since the caps are usually quite low, we assume they are binding, which allows us to create one local support variable (either the lump sum subsidy or the cap).

Other studies have shown that local support policy can influence adoption behavior (Jager (2006), Kwan (2012)). While these local measures were quantitatively less important than the policies imposed by the Flemish government, they can still indirectly be informative about the impact of these other policies.

9 Note that there is no need to include a measure of dispersion for the other included socio-demographic variables. For these variables dispersion is captured through multiple categories such as, for example, different categories for age, occupation, education or house size categories.

10 The data was downloaded from http://www.npdata.be/BuG/159-Verkiezingen-2012/Verkiezingen-2012.htm and the source mentioned was: vlaanderenkiest.be.

11 Meulewaeter et al. (2014) show that the green and socialist parties are comparatively closest to each other. Further information can also be found on the website of the Partirep project (www.partirep.eu/). 


\begin{tabular}{|c|c|c|c|}
\hline VARIABLES & $N$ & mean & St.dev. \\
\hline Total count of PV & 9.182 & 23.66 & 24.87 \\
\hline Total capacity of PV in kW & 9,182 & 113.6 & 119.3 \\
\hline Average capacity of PV & 8,542 & 4.972 & 1.268 \\
\hline Households (log) & 8,991 & 5.035 & 1.318 \\
\hline Income: average (log) & 8,504 & 10.51 & 0.226 \\
\hline Income: dispersion (log) & 8,504 & 4.657 & 0.207 \\
\hline Subsidy (1000EUR) & 9,182 & 0.138 & 0.209 \\
\hline House value: $<$ EUR500 & 8,998 & 0.222 & 0.185 \\
\hline House value: EUR500-EUR744 & 8,998 & 0.237 & 0.141 \\
\hline House value: EUR745-EUR999 & 8,998 & 0.185 & 0.111 \\
\hline House value: EUR1000-EUR1499 & 8,998 & 0.226 & 0.151 \\
\hline House value: EUR1500-EUR2499 & 8,998 & 0.100 & 0.134 \\
\hline House value: >EUR2500 & 8,998 & 0.0293 & 0.0975 \\
\hline Population density (log) & 8,978 & 6.300 & 1.765 \\
\hline Age: $<25$ & 8,647 & 0.0153 & 0.0215 \\
\hline Age: $25-34$ & 8,647 & 0.117 & 0.0563 \\
\hline Age: $34-44$ & 8,647 & 0.201 & 0.0561 \\
\hline Age: 45-65 & 8,647 & 0.394 & 0.0829 \\
\hline Age: $>65$ & 8,647 & 0.272 & 0.0793 \\
\hline Educ: other & 8,979 & 0.0610 & 0.0665 \\
\hline Educ: no high school & 8,979 & 0.378 & 0.113 \\
\hline Educ: high school & 8,979 & 0.300 & 0.0752 \\
\hline Educ: college & 8,979 & 0.261 & 0.109 \\
\hline Foreigners & 8,991 & 0.0479 & 0.0787 \\
\hline Left votes & 9,182 & 0.155 & 0.100 \\
\hline Environmental awareness & 8,989 & 0.871 & 0.115 \\
\hline House owner & 8,986 & 0.780 & 0.171 \\
\hline Household size: 1 & 8,647 & 0.250 & 0.107 \\
\hline Household size: 2 & 8,647 & 0.347 & 0.0643 \\
\hline Household size: 3 or 4 & 8,647 & 0.328 & 0.0878 \\
\hline Household size: $>4$ & 8,647 & 0.0743 & 0.0401 \\
\hline Male & 8,991 & 0.500 & 0.0462 \\
\hline Occup: other & 8,964 & 0.0217 & 0.0277 \\
\hline Occup: blue coll priv sector & 8,964 & 0.258 & 0.113 \\
\hline Occup: white coll priv sector & 8,964 & 0.329 & 0.108 \\
\hline Occup: self-employed & 8,964 & 0.164 & 0.105 \\
\hline Occup: public sector & 8,964 & 0.227 & 0.0906 \\
\hline House age: before 1971 & 9,021 & 0.567 & 0.232 \\
\hline House age: 1971-1980 & 9,021 & 0.145 & 0.132 \\
\hline House age: 1981-1990 & 9,021 & 0.102 & 0.100 \\
\hline House age: $1991-2000$ & 9,021 & 0.108 & 0.0941 \\
\hline House age: after 2000 & 9,021 & 0.0779 & 0.0768 \\
\hline House size $<45 \mathrm{~m} 2$ & 8,998 & 0.0121 & 0.0420 \\
\hline House size $45-64 m 2$ & 8,998 & 0.0506 & 0.0906 \\
\hline House size 65-104m2 & 8,998 & 0.227 & 0.181 \\
\hline House size $105-184 m 2$ & 8,998 & 0.455 & 0.172 \\
\hline House size $>184 \mathrm{~m} 2$ & 8,998 & 0.256 & 0.193 \\
\hline House type: detached & 9,014 & 0.531 & 0.317 \\
\hline House type: semi-detached & 9,014 & 0.206 & 0.149 \\
\hline House type: terraced & 9,014 & 0.183 & 0.223 \\
\hline House type: apartment & 9,014 & 0.0795 & 0.165 \\
\hline Double glazing & 8,982 & 0.737 & 0.118 \\
\hline Roof insulation & 8,977 & 0.581 & 0.135 \\
\hline Roof: good condition & 8,986 & 0.826 & 0.0793 \\
\hline
\end{tabular}

Table 2: Summary statistics 


\section{THE MODEL}

As discussed in the previous section, we combine the VREG database on PV installations with demographic data at the quite disaggregate level of the statistical sector. We model the total count of PV installations in a statistical sector at a particular date as a function of different groups of variables.

To motivate our model, Figure 2 shows the distribution of the main dependent variable: the number of PV installations per statistical sector.

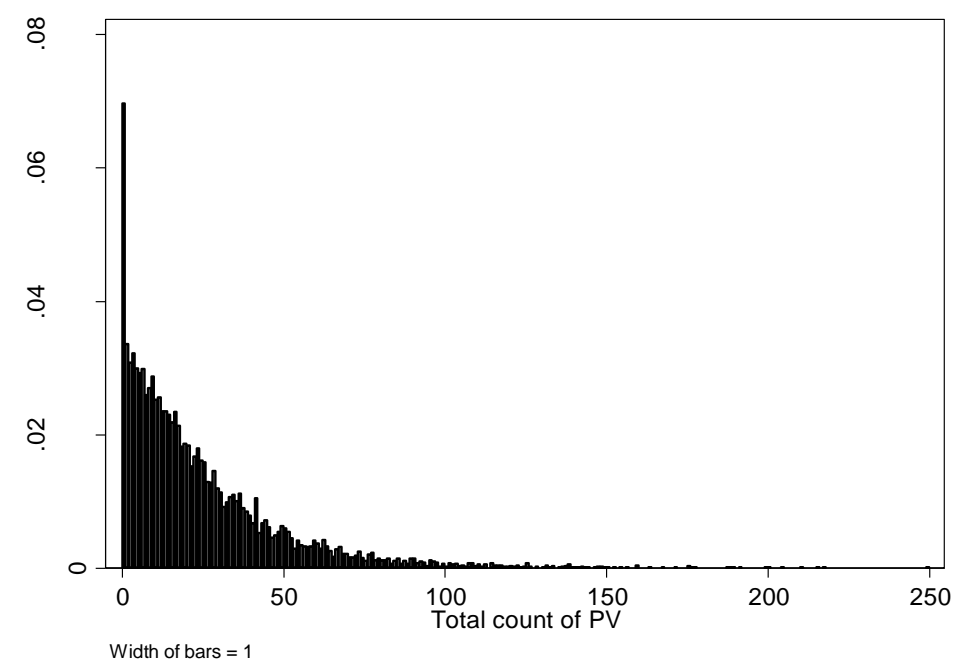

Figure 2: Distribution of the number of PVs per statistical sector (situation December 2012).

To analyze these count data, we focus on a Poisson regression model with robust standard errors. This model assumes that the outcome variable, the number of PV installations, follows a Poisson distribution. More specifically, the conditional mean function in the Poisson model has the exponential form:

$$
E\left[P V_{i} \mid \mathbf{x}_{i}\right]=\exp \left(\mathbf{x}_{i}^{\prime} \beta+\gamma \ln \left(\# \text { households }_{i}\right)+\eta_{m}\right)
$$

where $P V_{i}$ is the total number of PVs in statistical sector $i, \beta$ measures the effect of the covariates in vector $\mathbf{x}_{i}, \gamma$ is the elasticity with respect to the number of households and $\eta_{m}$ is a municipality fixed effect for statistical sector $i$ belonging to municipality $m$. Because of the exponential form, the parameters can be interpreted as semi-elasticities for linear regressors and as elasticities for regressors in log-form. Note that the number of households controls for the fact that statistical sectors are not of equal population size. We expect the number of PVs to rise proportionally to the number of households, $\gamma=1$.

A potential issue with the Poisson distribution is the violation of the equidispersion property, according to which the conditional variance of the outcome is equal to the conditional mean. However, to obtain consistent parameter estimates, only a correct specification of the conditional mean is required. Misspecification of the variance function may still affect the standard errors, which we correct using the standard sandwich covariance matrix, as suggested by Santos Silva and Tenreyro (2006). ${ }^{12}$

12 Because the Poisson model does not require a correct specification of the variance function, we do not extend the model to a negative binomial specification, which relaxes the equidispersion property by allowing for a more flexible variance function. For a more elaborate discussion on count data models, see Cameron and Trivedi (2013). They also explain that a negative binomial regression can be consistent if only the conditional mean is correctly specified, provided that the NB2 type is chosen. 
Another potential issue is that the model does not separately deal with the occurrence of zeros, as is done in zero-inflated count models. Kwan (2012) used a Zero-Inflated Negative Binomial (ZINB) model to study PV adoption in the US. A ZINB model consists of a Negative Binomial (NB) count regression model for most of the data, and a separate binary choice model to estimate the zero values outside the NB model (excess zeros). We prefer the Poisson model in our application for several reasons. First, the magnitude and significance of the parameter estimates from this model are easier to interpret. Second, the number of statistical sectors with zero values for the number of PV installations is relatively low in our sample (6.9\%). Furthermore, simulation evidence suggests that the estimates obtained with a Poisson model remain reliable even with a large number of zeros (Santos Silva and Tenreyro (2011)). Finally, the estimates from commonly used zero-inflated models such as the Zero-Inflated Poisson or ZINB are not robust to distributional misspecification, so that inference on the estimated parameters may be biased. ${ }^{13}$ In the appendix we nevertheless show that our results are robust for the alternatives considered here.

We made several adjustments to the model to deal with the spatial patterns in our data. Since the 9182 statistical sectors are clustered in the 308 municipalities of Flanders, we include fixed effects $\eta_{m}$ for every municipality. We thus control for unobserved heterogeneity at the municipality level. A further adjustment is made on the covariance matrix of the estimates. Since we can assume correlation is present between the residuals of sectors within the same municipality, we use clustered robust standard errors.

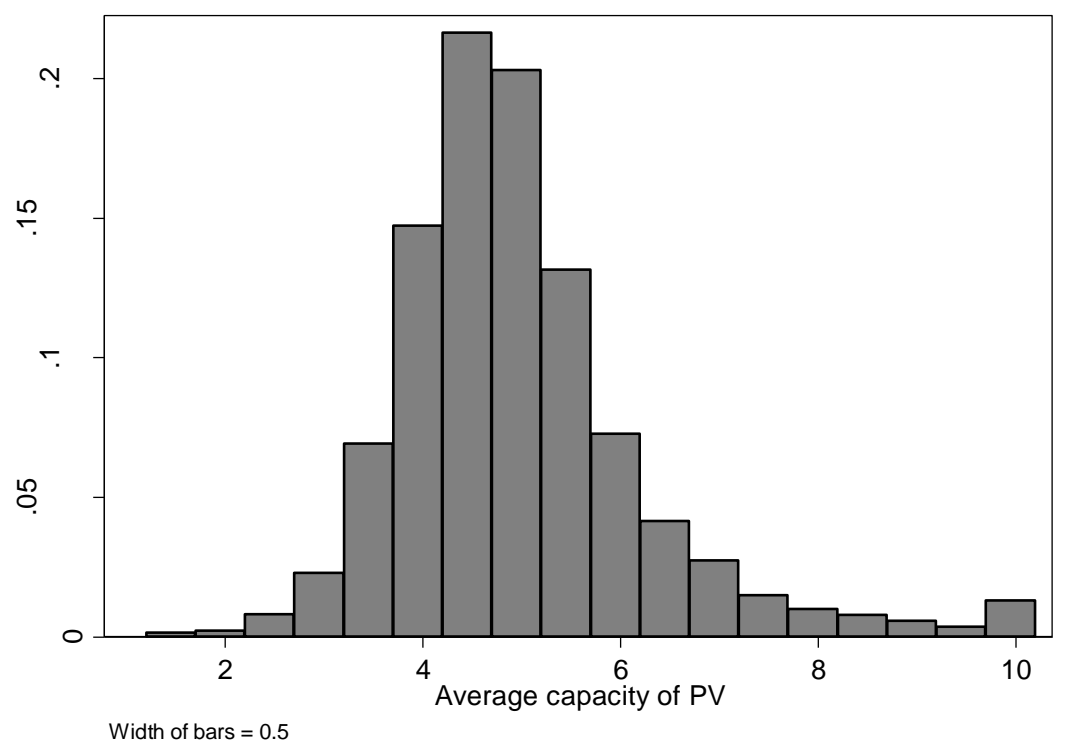

Figure 3: Distribution of the average capacity of PVs per statistical sector (situation December 2012)

Because the Poisson model already includes a full set of municipality fixed effects $\eta_{m}$, we cannot separately identify the effect of variables observed at the municipality level (subsidy and left votes). A standard solution is to perform an OLS regression of the first-stage estimated fixed effects $\eta_{m}$ on the municipality-level variables and a constant in a second stage. To obtain consistent standard errors, we estimate both stages simultaneously in a Generalized Method of Moments framework, by converting both the Poisson maximum likelihood estimator and the OLS regression to moment conditions (Newey (1984)).

In addition to explaining the number of PV installations per statistical sector, we will also look at the size of a PV, i.e. the average installed capacity. Figure 3 shows the distribution of the average

13 A solution would be to use a Zero-inflated Poisson Quasi-likelihood model. But with a low number of zeros, as in our sample, this would be more sensitive to finite sample bias (Staub and Winkelmann (2013)). 
size of PV installations across statistical sectors. It is worth noting that the Poisson model can still be used to estimate the effects of the various determinants. In fact, Santos Silva and Tenreyro (2006) show that because consistent estimation only requires the correct specification of the conditional mean, it is also preferred to analyze continuous dependent variables if researchers are interested in estimating (semi-)elasticities. We therefore continue to use the Poisson model to explain the average installed capacity (as well as total installed capacity), but our results are robust for alternative estimators such as OLS.

\section{RESULTS}

This section discusses the empirical results. In section 5.1 we discuss the main model, which explains the total number of PV installations per statistical sector. Section 5.2 discusses the results for models with two alternative dependent variables: the average size of the PV installations and the total installed capacity. These models focus on the situation as registered at the end of 2012. In section 5.3 we distinguish between two periods, identified on the basis of structural changes in the Flemish and local support mechanisms that were put in place.

Note that the categorical covariates are relative proportions of a particular characteristic in the statistical sector, expressed as a fraction of the total number of inhabitants, households or houses. Since the various sets of categorical covariates add up to one, we exclude one covariate per set, and interpret these as the reference groups. The tables below explicitly show these reference groups with a coefficient set to zero.

\subsection{Main model: explaining the adoption of $P V$}

Table 3 summarizes the results for various Poisson regressions to explain the number of PV installations. Model 1 includes a set of economic and social variables similar to Kwan (2012). Model 2 includes additional social variables for which we have information. Finally, Model 3 is the richest specification as it also includes a new set of housing characteristics.

For all models, the municipality fixed effects were jointly significant. Furthermore, for all models the coefficient for the number of households $\gamma$ is very close to 1 , and for the second and third model the null hypothesis of $\gamma=\mathbf{1}$ cannot be rejected. This shows that the total number of PV installations increases proportionally with the number of households. ${ }^{14}$

\section{Model 1: basic socioeconomic variables}

Model 1 includes a set of variables as close as possible to the ones considered by Kwan (2012), with two exceptions. First, we do not consider the cost of electricity in the set of economic variables, since this information is not available at the level of the statistical sector or municipality in Flanders, and electricity prices would likely not show sufficient regional variation to identify the effects. Second, we do not include solar radiation as an environmental variable, because this variable shows only limited variation within the region of Flanders. Generally speaking, unless we indicate otherwise, the results of Model 1 confirm the findings of Kwan (2012).

First consider the economic variables. Average income has a statistically significant and economically important effect on the number of PV installations, with an estimated income elasticity of 1.032. Note that this elasticity is conditional on the other variables included in the model. The unconditional income elasticity (without controlling for other variables) is even higher and is equal to 1.635. ${ }^{15}$ This reflects the fact that high income households have other characteristics that make them more likely to adopt, or live in houses or neighborhoods that are

\footnotetext{
14 In simpler specifications where we only include income or a limited set of variables, we found that $\gamma<1$, suggesting that the number of households then captures the effect of other variables omitted from the specification.

15 This unconditional elasticity of 1.635 , with a standard error of 0.247 , was obtained from a model without any other control variables and restricting $\gamma=1$. Since this model has no other parameters, we do not show it separately in the table.
} 
more suitable for PVs. The large unconditional effect of income indicates that a Matthew effect exists, i.e. wealthier households benefit proportionally more from the government support policies for PV as they have higher adoption rates.

The dispersion of income within a statistical sector plays a significant role. An increase in income dispersion, as measured by the interquartile coefficient, raises PV adoption. Hence, income distribution matters, presumably because adoption mainly takes place by the upper tail of the distribution. Note that this is different from Kwan's finding where the highest income category adopts less than middle income households.

The value of a house, measured by cadastral income (or land registry income), has a significant effect on the number of PV installations, in line with the findings of Kwan (2012). Generally speaking, the number of PV installations first increases in the house value, but at a certain point it becomes decreasing until the impact becomes insignificant (relative to the reference group for the lowest house value).

Local subsidies for PV have a positive and statistically significant effect, with an estimated semielasticity of 0.221 . The elasticity decreases only marginally to 0.176 when adding additional control variables, suggesting it is not largely driven by the effect of correlated unobservables. This estimate implies that a doubling of the local subsidy rate (say from the €138 to €276 in an average municipality) would increase adoption by $2.46 \% .{ }^{16}$ As we discussed in section 2 , the local subsidies were only a small part of the subsidies given in Flanders. This suggests that subsidization can be very effective in promoting PV. In fact, the main subsidy benefits came from the green certificates, which were granted at the regional level and were about $€ 10,000$ for an average system $(5 \mathrm{~kW})$ during the considered period. Our estimate of the local subsidy effect then suggests that without the Green Certificates the total number of adoptions in the average municipality would have been $82.8 \%$ lower. ${ }^{17}$

Now consider the social variables. Population density has a significant negative impact on PV adoption, with an elasticity of about -0.1 . This can be expected since in urbanized areas there is less space to install PVs on top of roofs. The household age also plays a significant role. Compared with the reference group with age below 25 , all other age groups have a much higher propensity to adopt. This propensity is highest for the age group 34-44, followed by the age group 25-34. These are typically the age groups that build or renovate new houses in Flanders. Note however that household age becomes unimportant once we control for more variables in Model 2 and 3, discussed below. Perhaps surprisingly, and also in contrast with Kwan (2012), education does not have a positive impact on PV adoption: a high school degree has an insignificant effect and college degree even seems to reduce the adoption rate. This may reflect a higher opportunity cost of time, or it may be due to omitted variables that are correlated with college education. The latter explanation is more likely because in our richer specifications below, education has no significant effect or only a significant effect in the early years.

As predicted by the literature, ethnicity plays a significant and important role in PV adoption: an increase in the number of foreigners by $1 \%$ point reduces the number of PV installations by $0.38 \%$. Even after adding control variables, the effect remains large at $0.21 \%$. This may reflect disparities in the support for environmentalism and environmentally responsible practices across different ethnical groups (e.g. Johnson et al. (2004) as discussed in Kwan (2012)).

Finally, the percentage of left votes has an insignificant effect on PV adoption. This differs from Kwan (2012), who found a significant positive effect.

\footnotetext{
16 To compute the exact effect of a policy change, write the expected number of adopters in municipality $i$ as $E\left(P V_{i}\right)=\exp \left(\beta s_{i}+\right.$ $A_{i}$ ), where $s_{i}$ is the subsidy (in €1000) with the estimated parameter $\beta=0.176$ and $A_{i}$ captures all other local determinants of adoption. Then the percentage change in the number of PVs after a change in subsidies $\Delta s_{i}$ is $\exp \left(0.176 \Delta s_{i}\right)-1$. Hence, with $\Delta s_{i}=0.138$ the percentage change is $\exp (0.176 \times 0.138)-1=0.0246$.

17 Similar to the previous footnote, with $\Delta s_{i}=-10$ the percentage change is $\exp (-0.176 \times 10)-1=-0.8280$.
} 


\begin{tabular}{|c|c|c|c|c|c|c|}
\hline \multirow{2}{*}{$\begin{array}{l}\text { VARIABLES } \\
\text { Households (log) }\end{array}$} & \multicolumn{2}{|c|}{ Model 1} & \multicolumn{2}{|c|}{$\begin{array}{c}\text { Model } 2 \\
\text { 1+extra hh char }\end{array}$} & \multicolumn{2}{|c|}{$\begin{array}{c}\text { Model } 3 \\
\text { 2+extra house }\end{array}$} \\
\hline & $0.960 *$ & $(0.009)$ & $0.997 *$ & 10.007 & $1.011^{*}$ & $(0.007)$ \\
\hline Income: average (log) & $1.032 *$ & (0.096) & 0.000 & $(0.065$ & 0.094 & (0.061) \\
\hline Income: dispersion (log) & $0.547^{*}$ & $(0.044)$ & $0.301 *$ & $(0.035$ & $0.152 *$ & $(0.034)$ \\
\hline Subsidy (1000EUR) & $0.221^{*}$ & $(0.101)$ & $0.190 *$ & $(0.075$ & $0.176^{*}$ & $(0.058)$ \\
\hline House value: <EUR500 & 0 & & 0 & & 0 & \\
\hline House value: EUR500-EUR744 & $0.407^{*}$ & $(0.067)$ & $0.485^{*}$ & $(0.065$ & 0.027 & (0.070) \\
\hline House value: EUR745-EUR999 & $0.682 *$ & $(0.077)$ & $0.602 *$ & $(0.066$ & 0.001 & $(0.063)$ \\
\hline House value: EUR1000-EUR1499 & $0.771^{*}$ & (0.103) & $0.791 *$ & $(0.076$ & 0.127 & $(0.076)$ \\
\hline House value: EUR1500-EUR2499 & $0.369 *$ & $(0.138)$ & $0.582 *$ & $(0.098$ & $-0.269 *$ & (0.091) \\
\hline House value: >EUR2500 & 0.044 & (0.206) & $0.275^{*}$ & $(0.130$ & $-0.732 *$ & (0.136) \\
\hline Population density (log) & - & $(0.006)$ & $-0.063 *$ & $(0.005$ & $-0.048 *$ & $(0.007)$ \\
\hline Age: $<25$ & 0 & & 0 & & 0 & \\
\hline Age: 25-34 & $7.945^{*}$ & $(0.927)$ & $1.457^{*}$ & $(0.576$ & 0.226 & (0.435) \\
\hline Age: $34-44$ & 9.099* & $(0.824)$ & $1.475^{*}$ & $(0.526$ & 0.318 & $(0.404)$ \\
\hline Age: 45-65 & $7.049 *$ & (0.833) & 0.568 & $(0.529$ & -0.454 & $(0.402)$ \\
\hline Age: $>65$ & $6.112^{*}$ & $(0.850)$ & 0.310 & $(0.544$ & -0.735 & $(0.403)$ \\
\hline Educ: no high school or other & 0 & & 0 & & 0 & \\
\hline Educ: High school & -0.149 & $(0.150)$ & -0.132 & $(0.125$ & 0.133 & (0.118) \\
\hline Educ: College & - & $(0.135)$ & $-0.330 *$ & $(0.116$ & 0.011 & (0.106) \\
\hline Foreigners & - & $(0.364)$ & $-2.766^{*}$ & $(0.269$ & $-2.118 *$ & $(0.230)$ \\
\hline Left votes & 0.097 & (0.232) & 0.128 & $(0.184$ & 0.203 & $(0.140)$ \\
\hline Environmental awareness & & & $2.330 *$ & (0.176 & $1.172 *$ & (0.161) \\
\hline House owner & & & $0.323 *$ & $(0.084$ & $0.383^{*}$ & $(0.068)$ \\
\hline Household size: 1 & & & 0 & & 0 & \\
\hline Household size: 2 & & & $0.948 *$ & $(0.130$ & $0.345^{*}$ & (0.117) \\
\hline Household size: 3 or 4 & & & $2.158^{*}$ & $(0.138$ & $1.056^{*}$ & $(0.122)$ \\
\hline Household size: >4 & & & $1.563^{*}$ & $(0.237$ & $0.860^{*}$ & (0.219) \\
\hline Male & & & 0.274 & $(0.198$ & 0.285 & $(0.186)$ \\
\hline Occup: blue coll priv sector and & & & 0 & & 0 & \\
\hline Occup: white coll priv sector & & & 0.078 & (0.119 & $0.284 *$ & (0.117) \\
\hline Occup: self-employed & & & -0.204 & $(0.111$ & 0.116 & $(0.123)$ \\
\hline Occup: public sector & & & 0.114 & $(0.131$ & $0.365^{*}$ & $(0.124)$ \\
\hline House age: before 1971 & & & & & 0 & \\
\hline House age: 1971-1980 & & & & & $0.320 *$ & (0.057) \\
\hline House age: $1981-1990$ & & & & & $0.484^{*}$ & $(0.061)$ \\
\hline House age: $1991-2000$ & & & & & $0.566^{*}$ & $(0.068)$ \\
\hline House age: after 2000 & & & & & $1.055^{*}$ & (0.077) \\
\hline House size <45m2 & & & & & 0 & \\
\hline House size $45-64 m 2$ & & & & & $1.340 *$ & (0.377) \\
\hline House size 65-104m2 & & & & & $1.675^{*}$ & $(0.362)$ \\
\hline House size $105-184 m 2$ & & & & & $2.281^{*}$ & $(0.357)$ \\
\hline House size >184m2 & & & & & $2.456^{*}$ & $(0.364)$ \\
\hline House type: detached & & & & & 0 & \\
\hline House type: semi-detached & & & & & $0.283^{*}$ & $(0.058)$ \\
\hline House type: terraced & & & & & 0.078 & $(0.057)$ \\
\hline House type: apartment & & & & & $-0.542 *$ & $(0.066)$ \\
\hline Double glazing & & & & & $0.344^{*}$ & $(0.075)$ \\
\hline Roof insulation & & & & & $-0.441^{*}$ & $(0.070)$ \\
\hline Roof: good condition & & & & & $0.443^{*}$ & $(0.115)$ \\
\hline Constant & - & $(1.161)$ & $-5.660 *$ & $(0.834$ & $-7.308^{*}$ & (0.788) \\
\hline Observations & 8472 & & 8471 & & 8471 & \\
\hline Loglikelihood 1st stage & - & & -28660 & & -27419 & \\
\hline $\mathrm{R}^{2}$ 2nd stage & 0.0153 & & 0.0199 & & 0.0360 & \\
\hline
\end{tabular}

Table 3: Estimation results for main model: total number of PV installations at the end of 2012 


\section{Model 2: additional household characteristics}

Model 2 extends the basic specification to include additional social variables, that were not included in previous studies.

In the 2001 census, households were asked about the presence of roof insulation in their house. We consider the fraction of households that was able to answer this question as a measure of environmental awareness and expect this fraction to have a positive impact on the number of PV systems adopted in a sector, which is confirmed by the results of Model 2.

House ownership status turns out to have a strong positive and statistically significant impact on PV adoption. Hence, PV adoption is more likely on the roofs of owned than on the roofs of rented houses. This is consistent with previous work, which has established that house renting forms a barrier to the adoption of new technologies within the house, as it is often difficult to allocate the benefits and the cost between tenants and landlords (Jaffe and Stavins (1994), Sutherland (1996)).

We also consider household size as a driver of PV adoption. We expect larger households to invest more in PV, because they are larger consumers of electricity and because they can spread the fixed costs of adoption over more household members; see also Mills and Schleich (2009) for a discussion on the relation between household size and technology. This is confirmed by the estimates: compared with the reference group of singles, households with 2 and especially with 3-4 members are much more likely to adopt a PV. Households with more than 4 members also invest significantly more in PV, but less so than households of 3 or 4 persons.

Previous studies have suggested that gender influences technology adoption, e.g. Venkatesh et al. (2000). The share of male residents was included to test the hypothesis that male residents would have higher adoption rates. We only find weak support for this, as the effect is positive but estimated fairly imprecisely. As a further test, we included a variable to distinguish between the share of single male and single female households. According to this specification, single male households are significantly more likely to adopt than single female households.

Model 2 also includes occupational status as a social covariate, where occupation is defined as having a job in the public or private sector, being self-employed or being in another category. For private sector occupations we also distinguish between white collar and blue collar workers. Our results suggest that public sector employees are more likely to adopt, especially when compared with self-employed. This may be due to better information on subsidies within this group or greater environmental awareness. Note that this is only estimated sufficiently precisely after including the housing characteristics of model 3.

Including the above variables has a considerable impact on several of the variables included in the previous model, which was close the set-up of Kwan (2012). Most interestingly, the impact of average income becomes small and statistically insignificant. Hence, while income dispersion has a significant effect, average income has no direct effect on PV adoption. It only plays an indirect role, as it is correlated with several of the new variables included in Model 2, most notably with house ownership status and household size. ${ }^{18}$ The impact of house value essentially remains unchanged and significant. Finally, the age variables have a much smaller impact, conditional on the new included variables. This can be explained by the significant role of house ownership, which typically starts at a higher age than 25 .

\section{Model 3: adding housing characteristics}

Model 3 considers the role of a detailed set of housing characteristics: house age, house size and various measures of house conditions. The parameters of most of these variables are statistically

18 This conclusion is based on the results of several regressions where we extend Model 1 with different combinations of the variables we added in Model 2. The regression tables are not shown in this paper but are available upon request. 
significant with the expected sign. Furthermore, the inclusion of these housing characteristics makes some of the social variables less important.

Everything else constant, one may expect more PVs on the roofs of recently built houses. We indeed find that house age has a negative effect on PV adoption. With houses built before 1971 as the benchmark, the rate of adoption decreases with the age of the houses. A hypothesis test on the equality of the estimated effects was rejected for all consecutive periods, except for houses built between 1981 and 2000. By far the biggest adoption rate occurs in houses built after 2000 .

Note that after including house age there is no longer a significant impact of the owner's age on PV adoption. This suggests that it is not the owner's age per se but rather the age of the owner's house that influences PV adoption. ${ }^{19}$ The negative effect for the retired age group, marginally insignificant, could reflect the fact that older generations have less concern for global warming and environmental issues than younger generations or have a lower knowledge of the technology (Kwan (2012), Torgler et al. (2008), Carlsson-Kanyama et al. (2005)). Alternatively, this result could also be due to the retired age group using a higher discount rate as they might take into account the eventuality of not living long enough to reap all the investment benefits (Harrison et al. (2002), Read and Read (2004) and Sozou and Seymour (2003)). However, this may not be the only reason for the lower adoption rates of older people, as houses can be resold at a higher market value that incorporates the PV installation and the associated subsidy rights.

One may also expect the size of the house, measured as the size of the built-up area, to have a positive impact on PV adoption (Walsh (1989), Mills and Schleich (2010)). This is indeed the case: a larger size raises the probability of adoption relative to the reference case of a built-up area of less than $45 \mathrm{~m}^{2}$. Houses in this reference category probably have insufficient roof surface to install a PV, let alone with the desired capacity. Larger house sizes typically have a larger roof surface, giving more flexibility to avoid disturbances on the roof (shadow from trees or chimneys, window vents...) and thus resulting in an increased probability of adoption. With an average electricity consumption of about $4000 \mathrm{kWh}$, most households would require an installation of about $5 \mathrm{kWp}$ which, under ideal conditions, requires a roof surface of about $40 \mathrm{~m}^{2}$. We therefore expect decreasing returns in size.

Although including house size reduces the previously estimated effect of household size, it is interesting to note that the effect of household size remains highly significant. Hence, size matters for both a technological reason (larger roofs) and a demand reason (more return on investment when electricity consumption is higher).

Regarding the house type, we distinguish between apartments, (semi-)detached and terraced houses, with detached houses as the reference category. As expected, areas with a relatively larger share of apartments have lower adoption rates. Also terraced houses have difficulties in installing PVs. Perhaps somewhat surprisingly, we find a stronger effect for semi-detached houses.

We include two proxies for the energy efficiency status of the house: double glazing and roof insulation. Both measures point in different directions. In line with our intuition, a one percentage point increase in the share of houses with double glazing will result in a statistically significant increase in the number of PVs adopted of $0.34 \%$. However, a one percentage point increase in the share of houses with roof insulation decreases the number of PVs adopted with a significant $0.44 \%$. One explanation for the latter result is that the data on roof insulation date from 2001, whereas the data on PV adoption date from 2006 or later. Over the last decade, the Flemish government has made efforts to stimulate households to invest in energy efficiency and in particular in roof insulation (through financial incentives and information provision). Over the

19 The correlations between household age categories and house age categories (both expressed as the proportion of households/houses in a statistical sector to be found in that age category) reveals a statistically significant and positive correlation between household age and house age for all age categories. For example, statistical sectors with a relatively high(er) proportion of households in the age range 45-64 also tend to have a higher proportion of older houses. The only notable exception is that statistical sectors with a higher proportion of houses built before 1970 also tend to have a higher proportion of young households. This can be explained by the fact that old houses are typically bought by or bequeathed to younger households. 
period 2006-2012 more than 285,000 dwellings received a subsidy for roof insulation (Vlaams Energieagenschap (2013)). We conjecture that this financial incentive for roof insulation triggered landlords or tenants to invest in PVs while also improving the roof insulation. We also find that roof quality has a positive impact on PV adoption. This is consistent with our expectation that a better roof quality involves lower investment costs. ${ }^{20}$

Note finally that once we include the housing characteristics, the previously estimated positive effects for the house value drop considerably: they either become insignificant and, for the highest house values, even show a negative impact. This suggests that the included housing characteristics are important to explain adoption behavior, and the value of the house served as a proxy for these in Model 1 and 2. This comes as no surprise as it is in line with what hedonic pricing models predict: the value of a product is determined by the characteristics of that product. The fact that the impact of the highest house values, conditional on other housing characteristics, is negative, may indicate that these houses, or their inhabitants, have certain unobserved characteristics that make PV adoption less likely. One of these unobserved characteristics is the esthetics of a house. This usually becomes more important for expensive houses, and PVs generally tend to degrade the looks of the house.

\subsection{Explaining the size of the adopted PV installations}

The previous analysis considered the determinants of the total number of PV installations. We now consider the determinants of the total installed capacity and the average size of these installations. Table 4 shows the results of the Poisson models, with the same set of explanatory variables as in Model 3. For ease of comparison, the two left columns again show the results for the total number of PV installations (Model 3). The middle two columns show the results for the total capacity of PV (Model 4) and the right two columns show the results for the average size (Model 5).

In general, the determinants of adoption (Model 3) and of total capacity (Model 4) are very similar. This can be explained by looking at the effects on the average size of an installation (Model 5 ), as most variables turn out to be insignificant.

There are, however, some interesting cases where a variable affects both the number of installations and the average size of an installation in the same direction. First, foreigners not only tend to adopt less, but they also invest in smaller PV systems. Second, in areas with a high population density both the number of installations and the average size tend to be lower. Finally, in houses with double glazing both the adoption rate and the average size of adoption are larger. As a result, for these variables the count effect and the size effect reinforce each other, so these variables have an even stronger impact on total installed capacity.

There are also some cases where a variable affects the number of installations and the average size of an installation in the opposite direction. Most interestingly, house owners (as opposed to renters) and white collar employees have a higher adoption rate, but they invest in smaller average sizes. The same is true for houses built after 2000: these have a higher adoption rate but a smaller average size. This may be because more recently built houses tend to be smaller or more energy efficient than older houses. For these variables the count effect is counteracted by the size effect, but in all cases it appears that the count effect dominates, so that the variables have qualitatively the same impact on the number of installations as on the total installed capacity.

\footnotetext{
20 Note that roof quality is correlated with, but not the same as having roof insulation. To assess whether roof quality (partly) picks up the impact of roof insulation, we estimated a model without the variable roof quality. This gave almost the same estimate for the impact of roof insulation.
} 


\begin{tabular}{|c|c|c|c|c|c|c|}
\hline \multirow{2}{*}{$\begin{array}{l}\text { VARIABLES } \\
\text { Households (log) }\end{array}$} & \multicolumn{2}{|c|}{$\begin{array}{c}\text { Model } 3 \\
\text { (total number) }\end{array}$} & \multicolumn{2}{|c|}{$\begin{array}{c}\text { Model } 4 \\
\text { (total capacity) }\end{array}$} & \multicolumn{2}{|c|}{$\begin{array}{c}\text { Model } 5 \\
\text { (average size) }\end{array}$} \\
\hline & $1.011 *$ & $(0.007)$ & $1.000^{*}$ & $(0.007)$ & $-0.013^{*}$ & $(0.003)$ \\
\hline Income: average (log) & 0.094 & $(0.061)$ & 0.061 & $(0.067)$ & 0.014 & $(0.025)$ \\
\hline Income: dispersion (log) & $0.152 *$ & (0.034) & $0.114 *$ & $(0.035)$ & -0.027 & $(0.016)$ \\
\hline Subsidy (1000EUR) & $0.176^{*}$ & $(0.058)$ & $0.186^{*}$ & $(0.063)$ & 0.007 & $(0.023)$ \\
\hline House value: <EUR500 & 0 & & 0 & & 0 & \\
\hline House value: EUR500- & 0.027 & $(0.070)$ & -0.025 & (0.073) & -0.052 & (0.035) \\
\hline House value: EUR745- & 0.001 & $(0.063)$ & -0.048 & $(0.072)$ & -0.027 & $(0.037)$ \\
\hline House value: EUR1000- & 0.127 & $(0.076)$ & 0.102 & (0.078) & -0.011 & $(0.032)$ \\
\hline House value: EUR1500- & $-0.269 *$ & (0.091) & $-0.252^{*}$ & $(0.100)$ & $0.076 *$ & $(0.038)$ \\
\hline House value: >EUR2500 & $-0.732 *$ & $(0.136)$ & $-0.823 *$ & $(0.140)$ & 0.051 & $(0.065)$ \\
\hline Population density (log) & $-0.048 *$ & (0.007) & $-0.065^{*}$ & (0.007) & $-0.024 *$ & $(0.003)$ \\
\hline Age: $<25$ & 0 & & 0 & & 0 & \\
\hline Age: 25-34 & 0.226 & (0.435) & 0.308 & (0.473) & $0.428 *$ & (0.209) \\
\hline Age: 34-44 & 0.318 & (0.404) & 0.367 & $(0.430)$ & 0.245 & (0.195) \\
\hline Age: $45-65$ & -0.454 & $(0.402)$ & -0.450 & $(0.431)$ & 0.233 & (0.191) \\
\hline Age: $>65$ & -0.735 & (0.403) & -0.747 & $(0.435)$ & 0.163 & $(0.185)$ \\
\hline Educ: no high school or other & 0 & & 0 & & 0 & \\
\hline Educ: High school & 0.133 & $(0.118)$ & 0.232 & (0.128) & 0.085 & $(0.064)$ \\
\hline Educ: College & 0.011 & (0.106) & -0.192 & (0.109) & $-0.209 *$ & $(0.057)$ \\
\hline Foreigners & $-2.118^{*}$ & $(0.230)$ & $-2.154^{*}$ & (0.229) & $-0.170 *$ & $(0.060)$ \\
\hline Left votes & 0.203 & $(0.140)$ & $0.367^{*}$ & (0.143) & $0.127^{*}$ & $(0.046)$ \\
\hline Environmental awareness & $1.172 *$ & 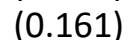 & $1.207^{*}$ & (0.173) & 0.116 & $(0.064)$ \\
\hline House owner & $0.383^{*}$ & $(0.068)$ & $0.214^{*}$ & $(0.072)$ & $-0.206^{*}$ & $(0.036)$ \\
\hline Household size: 1 & 0 & & 0 & & 0 & \\
\hline Household size: 2 & $0.345^{*}$ & (0.117) & $0.373^{*}$ & (0.124) & 0.002 & $(0.058)$ \\
\hline Household size: 3 or 4 & $1.056^{*}$ & $(0.122)$ & $1.212^{*}$ & (0.130) & 0.107 & $(0.066)$ \\
\hline Household size: >4 & $0.860 *$ & 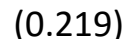 & $1.115^{*}$ & (0.243) & 0.100 & $(0.080)$ \\
\hline Male & 0.285 & $(0.186)$ & $0.399 *$ & $(0.192)$ & $0.250^{*}$ & (0.109) \\
\hline Occup: blue coll priv sector & 0 & & 0 & & 0 & \\
\hline Occup: white coll priv sector & $0.284 *$ & (0.117) & 0.141 & (0.119) & $-0.189 *$ & $(0.063)$ \\
\hline Occup: self-employed & 0.116 & $(0.123)$ & $0.937^{*}$ & (0.131) & $0.652 *$ & $(0.056)$ \\
\hline Occup: public sector & $0.365^{*}$ & $(0.124)$ & 0.224 & $(0.135)$ & $-0.205^{*}$ & $(0.066)$ \\
\hline House age: before 1971 & 0 & & 0 & & 0 & \\
\hline House age: 1971-1980 & $0.320^{*}$ & $(0.057)$ & $0.359 *$ & $(0.060)$ & 0.011 & $(0.026)$ \\
\hline House age: 1981-1990 & $0.484 *$ & (0.061) & $0.516^{*}$ & $(0.062)$ & -0.031 & $(0.033)$ \\
\hline House age: 1991-2000 & $0.566^{*}$ & 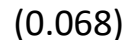 & $0.565^{*}$ & $(0.075)$ & -0.014 & $(0.040)$ \\
\hline House age: after 2000 & $1.055^{*}$ & $(0.077)$ & $0.945 *$ & $(0.083)$ & $-0.138 *$ & (0.038) \\
\hline House size $<45 \mathrm{~m} 2$ & 0 & & 0 & & 0 & \\
\hline House size 45-64m2 & $1.340^{*}$ & $(0.377)$ & $1.326^{*}$ & $(0.400)$ & -0.052 & (0.141) \\
\hline House size $65-104 m 2$ & $1.675^{*}$ & $(0.362)$ & $1.690 *$ & $(0.375)$ & -0.043 & (0.111) \\
\hline House size $105-184 \mathrm{~m} 2$ & $2.281^{*}$ & $(0.357)$ & $2.379 *$ & (0.371) & 0.049 & (0.111) \\
\hline House size >184m2 & $2.456^{*}$ & $(0.364)$ & $2.738^{*}$ & (0.379) & 0.187 & (0.115) \\
\hline House type: detached & 0 & & 0 & & 0 & \\
\hline House type: semi-detached & $0.283^{*}$ & $(0.058)$ & $0.262 *$ & (0.058) & -0.002 & $(0.025)$ \\
\hline House type: terraced & 0.078 & $(0.057)$ & -0.031 & (0.059) & $-0.080 *$ & (0.029) \\
\hline House type: apartment & $-0.542 *$ & $(0.066)$ & $-0.563 *$ & $(0.070)$ & 0.034 & $(0.035)$ \\
\hline Double glazing & $0.344 *$ & $(0.075)$ & $0.424 *$ & (0.079) & $0.090 *$ & (0.039) \\
\hline Roof insulation & $-0.441 *$ & $(0.070)$ & $-0.424 *$ & $(0.080)$ & 0.011 & $(0.035)$ \\
\hline Roof: good condition & $0.443 *$ & (0.115) & $0.339 *$ & (0.123) & -0.063 & $(0.058)$ \\
\hline Constant & $-7.308^{*}$ & $(0.788)$ & $-5.140 *$ & $(0.873)$ & $1.540^{*}$ & $(0.376)$ \\
\hline Observations & 8471 & & 8471 & & 8311 & \\
\hline Loglikelihood 1st stage & -27419 & & -70883 & & -14881 & \\
\hline$R^{2}$ 2nd stage & 0.0360 & & 0.0531 & & 0.0346 & \\
\hline
\end{tabular}

Notes: Results from GMM estimation of Poisson model as discussed in the text. Robust standard errors in parentheses, clustered by municipality. ${ }^{*}$ indicates $p<0.05$. Dependent variable is resp. total number of PV installations, total installed capacity and average size at the end of 2012. Unless otherwise indicated, the explanatory variables are expressed as percentages. 0 -values indicate the variable is reference category.

Table 4: Estimation results for effect on capacity 
Finally, there are some variables that affect the average size but not the number of PV installations. Most notably, males and self-employed people are not more likely to adopt, but when they adopt they tend to invest in larger PVs. As a result, these variables have a positive impact on total capacity, despite having an insignificant impact on the number of PV installations. The same holds for left votes and for young households (25-34).

In sum, the effects on average capacity of foreigners (-), males ( + ), the 25-34 years age group (+) and left votes $(+)$ suggests that environmental and technological preferences should not be neglected when discussing PV size choices. In contrast, more natural determinants like house size or household size seem to be less important. Note however from the small differences between Model 3 and Model 4 that all variables, including the preference-related ones, seem to play a much more important role in deciding whether to adopt, rather than in deciding on the size.

\subsection{Understanding variation over time}

As discussed in section 2, the mass adoption of PV installations started in 2006 after the introduction of the green certificates subsidy program of the Flemish government. In this section we divide the sample in two periods to ask whether the influence of certain covariates changed over time as the subsidy program became less generous. The first period runs from January 1st, 2006 to December 31st, 2009. This corresponds to the period in which the initially announced path of minimum prices per green certificate was not questioned and was at its highest value (€450). The second period covers January 1 st 2010 up to December 31st, 2012. In 2010, the value of a green certificate decreased for the first time and at that point the public debate on the appropriateness of the level of the minimum prices started. This regularly led to new announcements of reduced subsidy amounts for the green certificates. These reduced subsidies received a considerable amount of public attention, and they were also more dramatic than the gradually declining investment expenses associated with installing a PV system. It is therefore interesting to compare both periods, to assess whether different determinants mattered after the policy change. Table 5 shows the results, comparing the determinants of PV adoption for both separate periods with the previous model we had for total adoptions. The last column shows the p-values of a Wald test whether the estimated parameters differ between both periods.

Many of the parameters do not change significantly over the two periods. We concentrate our discussion on those parameters that significantly changed over time. The first group consists of parameters that mainly played a role in the first period. We indicate this by shading the relevant parameters in grey during the first period (middle columns). The second group consists of parameters that mainly played a role in the second period. We indicate this by shading these parameters in grey during the second period (right columns).

First consider the variables that mainly played a role in the first period. Average income per household, which had a small and insignificant effect during the whole period, in fact had a positive impact during the first period (with an elasticity of 0.204 ), while it had essentially no impact during the second period. Recall that these elasticities are conditional on the other variables included in the model. The unconditional income elasticity also drops significantly from 1.9 to 1.5 (not reported in the tables). ${ }^{21}$ Hence, a Matthew effect is present throughout the full period, but it has declined during the second half. Note that this declined effect is precisely when the subsidy program became less generous. Similarly, we find that the impact of income dispersion became smaller during the second period.

\footnotetext{
21 The income elasticity during the first period was 1.941 with a standard error of 0.214 , and the income elasticity during the second period was 1.509 with a standard error of 0.261 . The chi $^{2}$-statistic of the Wald test of equality was 49.37 which corresponds to a p-value of 0.000 .
} 


\begin{tabular}{|c|c|c|c|c|c|c|c|}
\hline \multirow{3}{*}{$\begin{array}{l}\text { VARIABLES } \\
\text { Households (log) } \\
\text { Income: average (log) }\end{array}$} & \multicolumn{2}{|c|}{ Model 3} & \multicolumn{2}{|c|}{$\begin{array}{c}\text { Model } 6 \\
3 \text { in 2006-2009 }\end{array}$} & \multicolumn{2}{|c|}{$\begin{array}{c}\text { Model 7 } \\
3 \text { in 2010-2012 }\end{array}$} & \multirow{2}{*}{$\begin{array}{c}6=7 \\
\text { p-value } \\
0.383\end{array}$} \\
\hline & $1.011 *$ & $(0.007)$ & $1.018^{*}$ & $(0.010)$ & $1.009 *$ & $(0.007)$ & \\
\hline & 0.094 & $(0.061)$ & $0.204^{*}$ & $(0.072)$ & 0.048 & (0.069) & $0.041^{*}$ \\
\hline Income: dispersion (log) & $0.152 *$ & $(0.034)$ & $0.260 *$ & $(0.051)$ & $0.107^{*}$ & $(0.040)$ & $0.010 *$ \\
\hline Subsidy (1000EUR) & $0.176^{*}$ & $(0.058)$ & $0.187^{*}$ & $(0.080)$ & $0.158 *$ & $(0.066)$ & 0.743 \\
\hline House value: <EUR500 & 0 & & 0 & & & & \\
\hline EUR500-EUR744 & 0.027 & $(0.070)$ & 0.067 & $(0.099)$ & 0.010 & $(0.077)$ & 0.589 \\
\hline EUR745-EUR999 & 0.001 & $(0.063)$ & 0.052 & $(0.083)$ & -0.014 & $(0.078)$ & 0.532 \\
\hline EUR1000-EUR1499 & 0.127 & $(0.076)$ & $0.266^{*}$ & $(0.097)$ & 0.071 & $(0.081)$ & $0.037^{*}$ \\
\hline EUR1500-EUR2499 & $-0.269 *$ & $(0.091)$ & $-0.284^{*}$ & $(0.118)$ & $-0.273^{*}$ & $(0.104)$ & 0.931 \\
\hline >EUR2500 & $-0.732^{*}$ & $(0.136)$ & $-0.883^{*}$ & $(0.172)$ & $-0.652 *$ & $(0.149)$ & 0.162 \\
\hline Population dens (log) & $-0.048^{*}$ & $(0.007)$ & $-0.051^{*}$ & $(0.009)$ & $-0.047^{*}$ & $(0.007)$ & 0.583 \\
\hline Age: $<25$ & 0 & & 0 & & 0 & & \\
\hline Age: $25-34$ & 0.226 & $(0.435)$ & 0.201 & $(0.735)$ & 0.229 & $(0.466)$ & 0.971 \\
\hline Age: 34-44 & 0.318 & $(0.404)$ & 0.641 & $(0.716)$ & 0.199 & $(0.417)$ & 0.535 \\
\hline Age: $45-65$ & -0.454 & $(0.402)$ & -0.099 & $(0.672)$ & -0.613 & $(0.420)$ & 0.436 \\
\hline Age: $>65$ & -0.735 & $(0.403)$ & -0.405 & $(0.669)$ & $-0.870 *$ & $(0.425)$ & 0.482 \\
\hline Educ: no /other & 0 & & 0 & & 0 & & \\
\hline Educ: High school & 0.133 & $(0.118)$ & -0.101 & (0.199) & 0.237 & (0.129) & 0.110 \\
\hline Educ: College & 0.011 & $(0.106)$ & 0.311 & $(0.168)$ & -0.137 & $(0.117)$ & $0.013^{*}$ \\
\hline Foreigners & $-2.118^{*}$ & $(0.230)$ & $-2.520 *$ & (0.304) & $-1.989 *$ & $(0.231)$ & $0.031 *$ \\
\hline Left votes & 0.203 & $(0.140)$ & -0.023 & $(0.196)$ & 0.284 & $(0.148)$ & 0.096 \\
\hline Environmental aware. & $1.172 *$ & $(0.161)$ & $0.795^{*}$ & $(0.230)$ & $1.336^{*}$ & $(0.160)$ & $0.004 *$ \\
\hline House owner & $0.383^{*}$ & $(0.068)$ & $0.413^{*}$ & $(0.102)$ & $0.367^{*}$ & $(0.073)$ & 0.655 \\
\hline Household size: 1 & 0 & & 0 & & 0 & & \\
\hline Household size: 2 & $0.345^{*}$ & $(0.117)$ & 0.269 & $(0.174)$ & $0.373^{*}$ & $(0.131)$ & 0.582 \\
\hline Household size: 3 or 4 & $1.056^{*}$ & $(0.122)$ & $1.007^{*}$ & (0.187) & $1.075^{*}$ & $(0.138)$ & 0.741 \\
\hline Household size: >4 & $0.860 *$ & $(0.219)$ & $1.565^{*}$ & (0.329) & $0.548^{*}$ & $(0.219)$ & $0.000 *$ \\
\hline Male & 0.285 & $(0.186)$ & $0.756^{*}$ & $(0.324)$ & 0.098 & $(0.209)$ & 0.071 \\
\hline Occup: blue coll/other & 0 & & 0 & & 0 & & \\
\hline Occup: white coll & $0.284^{*}$ & $(0.117)$ & $0.781^{*}$ & $(0.175)$ & 0.090 & (0.129) & $0.000 *$ \\
\hline Occup: self-employed & 0.116 & $(0.123)$ & -0.003 & $(0.163)$ & 0.170 & $(0.142)$ & 0.355 \\
\hline Occup: public sector & $0.365^{*}$ & $(0.124)$ & $0.676^{*}$ & $(0.172)$ & 0.262 & $(0.142)$ & $0.031 *$ \\
\hline House age: before 1971 & 0 & & 0 & & 0 & & \\
\hline House age: $1971-1980$ & $0.320 *$ & $(0.057)$ & $0.155^{*}$ & $(0.076)$ & $0.390 *$ & $(0.063)$ & $0.002 *$ \\
\hline House age: 1981-1990 & $0.484^{*}$ & $(0.061)$ & $0.474^{*}$ & (0.099) & $0.483^{*}$ & $(0.069)$ & 0.928 \\
\hline House age: 1991-2000 & $0.566^{*}$ & $(0.068)$ & $0.576^{*}$ & $(0.106)$ & $0.545^{*}$ & $(0.075)$ & 0.793 \\
\hline House age: after 2000 & $1.055^{*}$ & $(0.077)$ & $0.668^{*}$ & $(0.103)$ & $1.210^{*}$ & $(0.092)$ & $0.000 *$ \\
\hline House size $<45 \mathrm{~m} 2$ & 0 & & 0 & & 0 & & \\
\hline House size $45-64 m 2$ & $1.340^{*}$ & $(0.377)$ & $1.128^{*}$ & $(0.393)$ & $1.389 *$ & (0.419) & 0.478 \\
\hline House size $65-104 m 2$ & $1.675^{*}$ & $(0.362)$ & $1.415^{*}$ & $(0.358)$ & $1.753^{*}$ & $(0.401)$ & 0.287 \\
\hline House size $105-184 \mathrm{~m} 2$ & $2.281^{*}$ & $(0.357)$ & $2.182^{*}$ & $(0.364)$ & $2.292^{*}$ & (0.394) & 0.730 \\
\hline House size $>184 \mathrm{~m} 2$ & $2.456 *$ & $(0.364)$ & $2.306^{*}$ & $(0.369)$ & $2.501 *$ & $(0.398)$ & 0.532 \\
\hline House type: detached & 0 & & 0 & & 0 & & \\
\hline House type: semi-det. & $0.283^{*}$ & $(0.058)$ & $0.292^{*}$ & $(0.074)$ & $0.277^{*}$ & $(0.065)$ & 0.854 \\
\hline House type: terraced & 0.078 & $(0.057)$ & $0.240^{*}$ & $(0.075)$ & 0.018 & $(0.060)$ & $0.002 *$ \\
\hline House type: apartment & $-0.542 *$ & $(0.066)$ & $-0.502 *$ & $(0.087)$ & $-0.552 *$ & $(0.073)$ & 0.580 \\
\hline Double glazing & $0.344^{*}$ & $(0.075)$ & $0.445^{*}$ & $(0.123)$ & $0.309^{*}$ & $(0.086)$ & 0.333 \\
\hline Roof insulation & $-0.441^{*}$ & $(0.070)$ & $-0.422^{*}$ & $(0.107)$ & $-0.452^{*}$ & $(0.082)$ & 0.808 \\
\hline Roof: good condition & $0.443^{*}$ & $(0.115)$ & $0.503^{*}$ & $(0.159)$ & $0.434^{*}$ & $(0.129)$ & 0.683 \\
\hline Constant & $-7.308 *$ & $(0.788)$ & - & $(0.959)$ & $-6.612^{*}$ & $(0.891)$ & \\
\hline Observations & 8471 & & 8471 & & 8471 & & \\
\hline Loglikelihood 1st stage & -27419 & & -19675 & & -25286 & & \\
\hline $\mathrm{R}^{2}$ 2nd stage & 0.0360 & & 0.0172 & & 0.0341 & & \\
\hline
\end{tabular}

Table 5: Estimation results over time 
Among the household characteristics, a college or university degree had no significant effect over the entire period, but it does have a significant positive effect at the $10 \%$ level during the first period. This may relate to the higher information cost in the early periods: educated people may more quickly become aware of subsidy programs, though less educated people eventually catch up. We also did not find a significantly higher adoption rate for males over the whole period, but they do show a higher adoption rate during the first period. Large households (over 4 members) especially adopted during the first period, though even in the second period these households had a higher adoption rate. Next, the role of occupational status seems to have diminished over time: white collar and public sectors workers only show a larger adoption rate during the first period. Finally, terraced houses showed higher adoptions during the first period but not over the entire period.

Now consider the group of variables that mainly played a role in the second period, and less so in the first period. This is true for environmental awareness as it became more pronounced in the second period. One possible explanation for this effect could be the reduced financial incentives and thus the reduced profitability of installing PV in the second period: this allows environmental awareness to become a more prominent driver of adoption behavior. We also see an interesting result for house age, where houses of the 70s catch up with houses of the $80 \mathrm{~s}$ and $90 \mathrm{~s}$, and the youngest group shows a significantly higher adoption rate in the second period. This might result from the fact that households are credit constrained and unable to buy a PV right after a large investment in building a house. An alternative explanation relates to the VAT policy in Flanders, which allows a $6 \%$ instead of $21 \%$ VAT-rate to renovate houses that are at least 5 years old. Therefore households living in new houses have an incentive to postpone their investment to benefit from the reduced VAT-rate.

We conclude that our results are relatively robust over time. There are however some differences as college degrees and high incomes were only important in the beginning, perhaps because of initially higher information costs. We also find a stronger unconditional income elasticity during the first period, implying an even more important Matthew effect when subsidies were higher. Finally, new adopters often live in newer houses and they are relatively more aware of environmental issues (in light of the declined subsidies in the second period).

\section{SUMMARY AND CONCLUSION}

This paper has extended previous work on explaining the heterogeneity in PV adoption, by considering a much richer set of household characteristics and including a new set of housing characteristics in a single framework. Furthermore, this is one of the first studies that analyzes the complete installed base of PV in a region outside the US. More specifically, we combined various data sources to generate a comprehensive dataset for the entire region of Flanders, where PV adoption has reached high levels because of active government policies during 2006-2012. We used a Poisson model to quantify the relative importance of socioeconomic variables at a very small level of aggregation (on average 280 households).

We can summarize our findings of the main model as follows. First, local subsidies have a robust and significant impact on PV adoption in all specifications. While the local subsidies were quantitatively relatively modest, this finding is indirect evidence that the larger incentives at the regional level (mainly through green certificates and net metering) have formed the basis for the strong development of PV adoption in Flanders (and presumably in many other regions or countries).

Second, the unconditional income elasticity (without controlling for other covariates) is as high as 1.6, and even 1.9 in the first period when subsidies were at its highest level. This suggests a strong Matthew effect in the sense that richer households disproportionately benefited from the subsidies. The income elasticity is still a sizeable 1.032 if we control for a similar set of covariates as in Kwan. 
Our third main finding is, however, that the direct income effect almost vanishes if we also control for household size and house ownership. Larger households are more likely to adopt because they tend to consume more electricity and can spread the fixed investment costs over larger absolute savings in energy costs. House owners can reap a larger part of the benefits from their investments. We can thus explain the channel through which wealthier households are more likely to benefit from the PV subsidies: this is not because of their higher income per se, but rather because they are more likely to adopt PVs as high users and as more frequent house owners and because they live in houses that are better suited for PVs.

Our final main finding concerns the role of the housing characteristics, which has not been considered in previous work. We find that both house size and house age play an important role: PV adoption is more likely in larger and in more recently built houses. Interestingly, accounting for this information reduces the significance of house value, suggesting our included set of housing characteristics captures the most relevant aspects of housing in the adoption of PVs. Furthermore, accounting for house age also makes the impact of household age insignificant, indicating that younger households do not have stronger incentives per se to adopt PVs, but rather do this because they live in more recently built houses.

In a first extension we show that most of the considered covariates have a smaller impact on the capacity size of the installed PVs. This implies that most covariates have a similar impact on the total number of installations as on the total installed capacity. A surprising result is that natural covariates such as household size or house size do not appear to play an important role in explaining PV size. Instead, the variables that relate to environmental and technological preferences are important for the chosen size.

In a second extension we show that the impact of most covariates is stable over time, with some interesting exceptions. For example, education did not seem to play a significant role over the entire period 2006-2012. But college degrees have been faster adopters during 2006-2009. The most recent adopters (after 2009, when subsidies started to decline) often live in newer houses and have a stronger environmental awareness.

More generally speaking, our analysis shows that the inclusion of new covariates that are not included in other studies (probably due to a lack of availability), has an impact on the effects of the other covariates. As a result, some of the conclusions in earlier work may need qualification. In particular, it turns out that the direct impact of income, house value and household age is less important than previously found, while there is an important role for housing characteristics and household size. Finally, we show that heterogeneity not only plays a role in the decision to adopt, but also for the desired size and that there are some differences between early and late adopters.

This paper provides an elaborate overview of how heterogeneity plays a role in the diffusion of PV. Furthermore, it provides a first step towards a more elaborate analysis of the adoption of PV. Various other questions may be considered in future research. A first extension would be to further explore the role of peer effects, along the lines of Bollinger and Gillingham (2012), Letchford et al. (2014), Richter (2013) and Rode and Weber (2011), but after controlling for a richer set of covariates that may explain the heterogeneity in PV adoption across areas. A second line of future research will be to also look into the dynamics of PV adoption, to address questions such as 'What determines the rate of diffusion?', and 'What factors determine the timing of adoption?' 


\section{References}

Bollinger, B., Gillingham, K., 2012. Peer effects in the diffusion of solar photovoltaic panels. Marketing Science 31, 900-912.

Borenstein, S., Bushnell, J., 2015. The US Electricity Industry After 20 Years of Restructuring. National Bureau of Economic Research.

Cai, D.W.H., Adlakha, S., Low, S.H., De Martini, P., Mani Chandy, K., 2013. Impact of residential PV adoption on Retail Electricity Rates. Energy Policy 62, 830-843.

Cameron, A.C., Trivedi, P.K., 2013. Regression analysis of count data. Cambridge university press. Carlsson-Kanyama, A., Lindén, A.-L., Eriksson, B., 2005. Residential energy behaviour: does generation matter? International Journal of Consumer Studies 29, 239-253.

Crago, C., Chernyakhovskiy, I., 2014. Solar PV Technology Adoption in the United States: An Empirical Investigation of State Policy Effectiveness, 2014 Annual Meeting, July 27-29, 2014, Minneapolis, Minnesota. Agricultural and Applied Economics Association.

Darghouth, N.R., Barbose, G., Wiser, R., 2011. The impact of rate design and net metering on the bill savings from distributed PV for residential customers in California. Energy Policy 39, 52435253.

Dassonneville, R., Baudewyns, P., 2014. Volatility: much movement but no earthquake. Samenleving en politiek, 11.

Davidson, C., Drury, E., Lopez, A., Elmore, R., Margolis, R., 2014. Modeling photovoltaic diffusion: an analysis of geospatial datasets. Environmental Research Letters 9, 74009-74023.

Drury, E., Miller, M., Macal, C.M., Graziano, D.J., Heimiller, D., Ozik, J., Perry Iv, T.D., 2012. The transformation of southern California's residential photovoltaics market through third-party ownership. Energy Policy 42, 681-690.

Faiers, A., Neame, C., 2006. Consumer attitudes towards domestic solar power systems. Energy Policy 34, 1797-1806.

Fransson, N., Gärling, T., 1999. Environmental Concern: Conceptual Definitions, Measurement methods, and Research Findings. Journal of Environmental Psychology 19, 369-382.

Harrison, G.W., Lau, M.I., Williams, M.B., 2002. Estimating individual discount rates in Denmark: A field experiment. The American Economic Review 92, 1606-1617.

Hersch, J., Viscusi, W.K., 2006. The Generational Divide in Support for Environmental Policies: European Evidence. Climatic Change 77, 121-136.

Jaffe, A.P., Stavins, R., 1994. Energy efficiency investments and public policy. The Energy Journal $15,43-65$.

Jager, W., 2006. Stimulating the diffusion of photovoltaic systems: A behavioural perspective. Energy Policy 34, 1935-1943.

Johnson, C.Y., Bowker, J.M., Cordell, H.K., 2004. Ethnic Variation in Environmental Belief and Behavior: An Examination of the New Ecological Paradigm in a Social Psychological Context. Environment and Behavior 36, 157-186.

Kahn, M.E., Vaughn, R.K., 2009. Green market geography: The spatial clustering of hybrid vehicles and LEED registered buildings. The BE Journal of Economic Analysis \& Policy 9.

Kontogianni, A., Tourkolias, C., Skourtos, M., 2013. Renewables portfolio, individual preferences and social values towards RES technologies. Energy Policy 55, 467-476.

Kwan, C.L., 2012. Influence of local environmental, social, economic and political variables on the spatial distribution of residential solar PV arrays across the United States. Energy Policy 47, 332344.

Letchford, J., Lakkaraju, K., Vorobeychik, Y., 2014. Individual Household Modeling of Photovoltaic Adoption.

Macal, C.M., Graziano, D.J., Ozik, J., 2014. Modeling Solar PV Adoption: A Social-Behavioral AgentBased Framework.

Meulewaeter, C., Rihoux, B., Walgrave, S., Lesschaeve, C., 2014. Does Belgium still exist in Belgian Politics? Samenleving en politiek, 11. 
Mills, B.F., Schleich, J., 2009. Profits or preferences? Assessing the adoption of residential solar thermal technologies. Energy Policy 37, 4145-4154.

Mills, B.F., Schleich, J., 2010. Why don't households see the light?: Explaining the diffusion of compact fluorescent lamps. Resource and Energy Economics 32, 363-378.

Newey, W.K., 1984. A method of moments interpretation of sequential estimators. Economics Letters 14, 201-206.

Read, D., Read, N.L., 2004. Time discounting over the lifespan. Organizational Behavior and Human Decision Processes 94, 22-32.

Richter, L.-L., 2013. Social Effects in the Diffusion of solar Photovoltaic Technology in the UK. Faculty of Economics, University of Cambridge.

Robinson, S.A., Stringer, M., Rai, V., Tondon, A., 2013. Gis-integrated agent-based model of residential solar pv diffusion, 32nd USAEE/IAEE North American Conference, pp. 28-31.

Rode, J., Weber, A., 2011. Knowledge Does Not Fall Far from the Tree-A Case Study on the Diffusion of Solar Cells in Germany, ERSA conference papers. European Regional Science Association.

Santos Silva, J.M.C., Tenreyro, S., 2006. The Log of Gravity. The review of economics and statistics 88, 641-658.

Santos Silva, J.M.C., Tenreyro, S., 2011. Further simulation evidence on the performance of the Poisson pseudo-maximum likelihood estimator. Economics Letters 112, 220-222.

Schelly, C., 2014. Residential solar electricity adoption: What motivates, and what matters? A case study of early adopters. Energy Research \& Social Science 2, 183-191.

Sozou, P.D., Seymour, R.M., 2003. Augmented discounting: interaction between ageing and timepreference behaviour. Proceedings of the Royal Society B: Biological Sciences 270, 1047-1053.

Staub, K.E., Winkelmann, R., 2013. Consistent Estimation of Zero-Inflated Count Models. Health Economics 22, 673-686.

Sutherland, R.J., 1996. The economics of energy conservation policy. Energy Policy 24, 361-370. Torgler, B., Garia-Valinas, M., Macintyre, A., 2008. Differences in Preferences Towards the Environment: The Impact of a Gender, Age and Parental Effect." Fondazione Eni Enrico Mattei, Nota di lavorno, p. 39.

Vasseur, V., Kemp, R., 2015. The adoption of PV in the Netherlands: A statistical analysis of adoption factors. Renewable and Sustainable Energy Reviews 41, 483-494.

Venkatesh, V., Morris, M.G., Ackerman, P.L., 2000. A Longitudinal Field Investigation of Gender Differences in Individual Technology Adoption Decision-Making Processes. Organizational Behavior and Human Decision Processes 83, 33-60.

Verbruggen, A., 2004. Tradable green certificates in Flanders (Belgium). Energy Policy 32, 165176.

Verbruggen, A., 2009. Performance evaluation of renewable energy support policies, applied on Flanders' tradable certificates system. Energy Policy 37, 1385-1394.

Verhaegen, K., Meeus, L., Belmans, R., 2009. Towards an international tradable green certificate system--The challenging example of Belgium. Renewable and Sustainable Energy Reviews 13, 208-215.

Vlaams Energieagenschap, 2013. Jaarverslag 2012 van het Vlaams Energieagentschap. Vlaams Energieagentschap, Brussel, p. 67.

VREG, 2015. Certificatenmarktrapport 2014. VREG, Brussel, p. 45.

Walsh, M.J., 1989. Energy tax credits and housing improvement. Energy Economics 11, 275-284.

Willis, K., Scarpa, R., Gilroy, R., Hamza, N., 2011. Renewable energy adoption in an ageing population: Heterogeneity in preferences for micro-generation technology adoption. Energy Policy 39, 6021-6029. 


\section{APPENDIX A: ALTERNATIVE MODELS}

In this section we compare popular alternative models for our preferred specification (Model 3). We compare the Poisson model with a Negative Binomial (NB2) and their zero-inflated counterparts ZIP and ZINB. While the Poisson and NB2 model only require the conditional mean to be correctly specified, the ZIP and ZINB are not robust to misspecification of higher moments. We therefore also compare with the Staub and Winkelmann (2013) zero-inflated Poisson quasilikelihood approach (ZIPQL). Although this model provides consistent estimates without correct specification of higher moments, the low number of zero observations in our dataset can result in important small sample bias.

We use the same variables in both the count-part of the model and the binary part that explains the zeros, except for the municipality dummy variables. We exclude these dummy variables from the binary part of the model to avoid convergence problems, as this adds a lot of variables and we only have a limited number of zeros. For simplicity, we do not calculate the GMM covariance matrix but simply focus on the first stage of the model (so we do not perform a second stage regression of the municipality fixed effects on the municipality-level variables, left votes and local subsidy). We do not show the results of the binary part of the model but focus on the count part of the models as this is our main interest.

Table 6 shows that our estimates are robust. Not only is the qualitative interpretation the same but also the estimated coefficients are almost identical. This was expected for the Poisson and NB2 model, as consistent estimation only requires the correct specification of the conditional mean function, which is identical for both models. But also the zero-inflated models confirm the robustness of our results. Furthermore, note that the standard errors are similar because all estimators use the cluster-robust covariance matrix. 
26

\begin{tabular}{|c|c|c|c|c|c|c|c|c|c|c|}
\hline \multirow[t]{2}{*}{ VARIABLES } & \multicolumn{2}{|c|}{$\begin{array}{c}\text { Poisson } \\
\text { (first stage of model 3) }\end{array}$} & \multicolumn{2}{|c|}{ NB2 } & \multicolumn{2}{|c|}{ ZIP } & \multicolumn{2}{|c|}{ ZINB } & \multicolumn{2}{|c|}{ ZIPQL } \\
\hline & $1.011^{*}$ & $(0.007)$ & $1.009 *$ & $(0.007)$ & $1.008^{*}$ & $(0.007)$ & $1.005^{*}$ & $(0.007)$ & $0.979 *$ & $(0.011)$ \\
\hline Income: average (log) & 0.094 & $(0.061)$ & 0.088 & $(0.064)$ & 0.076 & $(0.060)$ & 0.062 & $(0.061)$ & -0.044 & $(0.067)$ \\
\hline Income: dispersion (log) & $0.152^{*}$ & $(0.034)$ & $0.148^{*}$ & $(0.037)$ & $0.154^{*}$ & $(0.034)$ & $0.151^{*}$ & $(0.037)$ & 0.061 & $(0.048)$ \\
\hline House value: $<$ EUR500 & 0 & & 0 & & & & & & & \\
\hline House value: EUR500-EUR744 & 0.027 & $(0.070)$ & -0.008 & $(0.072)$ & 0.026 & $(0.071)$ & -0.012 & $(0.073)$ & 0.080 & $(0.097)$ \\
\hline House value: EUR745-EUR999 & 0.001 & $(0.063)$ & 0.012 & $(0.065)$ & 0.006 & $(0.062)$ & 0.018 & $(0.062)$ & 0.017 & $(0.105)$ \\
\hline House value: EUR1000-EUR1499 & 0.127 & $(0.076)$ & 0.109 & $(0.075)$ & 0.134 & $(0.075)$ & 0.121 & $(0.072)$ & 0.133 & (0.111) \\
\hline House value: EUR1500-EUR2499 & $-0.269 *$ & $(0.092)$ & $-0.267^{*}$ & $(0.089)$ & $-0.253 *$ & $(0.090)$ & $-0.245 *$ & $(0.088)$ & -0.045 & $(0.140)$ \\
\hline House value: >EUR2500 & $-0.732 *$ & $(0.136)$ & $-0.782^{*}$ & $(0.138)$ & $-0.730 *$ & $(0.136)$ & $-0.779 *$ & $(0.135)$ & $-0.644^{*}$ & $(0.252)$ \\
\hline Population density (log) & $-0.048^{*}$ & $(0.007)$ & $-0.049 *$ & $(0.007)$ & $-0.047 *$ & $(0.006)$ & $-0.048^{*}$ & $(0.007)$ & -0.014 & $(0.010)$ \\
\hline Age: $<25$ & 0 & & & & & & & & & \\
\hline Age: $25-34$ & 0.226 & $(0.436)$ & 0.022 & $(0.451)$ & 0.284 & $(0.438)$ & 0.091 & $(0.448)$ & $1.018^{*}$ & $(0.510)$ \\
\hline Age: $34-44$ & 0.318 & $(0.404)$ & 0.125 & $(0.421)$ & 0.412 & $(0.412)$ & 0.224 & $(0.427)$ & $1.065^{*}$ & (0.497) \\
\hline Age: $45-65$ & -0.454 & $(0.403)$ & -0.684 & $(0.425)$ & -0.337 & (0.409) & -0.548 & $(0.430)$ & 0.669 & $(0.475)$ \\
\hline Age: $>65$ & -0.735 & $(0.404)$ & $-0.977^{*}$ & $(0.419)$ & -0.628 & $(0.413)$ & $-0.855^{*}$ & $(0.427)$ & 0.208 & $(0.475)$ \\
\hline Educ: no high school or other & 0 & & & & & & & & & \\
\hline Educ: High school & 0.133 & $(0.118)$ & 0.165 & $(0.125)$ & 0.112 & $(0.117)$ & 0.132 & $(0.122)$ & 0.044 & $(0.146)$ \\
\hline Educ: College & 0.011 & $(0.106)$ & 0.040 & $(0.104)$ & 0.014 & (0.105) & 0.044 & $(0.103)$ & -0.227 & $(0.182)$ \\
\hline Foreigners & $-2.118^{*}$ & $(0.230)$ & $-2.058^{*}$ & $(0.227)$ & $-2.100 *$ & $(0.227)$ & $-2.031^{*}$ & $(0.223)$ & $-1.619^{*}$ & (0.167) \\
\hline Environmental awareness & $1.172^{*}$ & $(0.161)$ & $1.243^{*}$ & $(0.162)$ & $1.096 *$ & $(0.156)$ & $1.151^{*}$ & $(0.164)$ & -0.022 & $(0.262)$ \\
\hline House owner & $0.383^{*}$ & $(0.068)$ & $0.390^{*}$ & $(0.071)$ & $0.392^{*}$ & $(0.068)$ & $0.395^{*}$ & $(0.072)$ & $0.435^{*}$ & $(0.105)$ \\
\hline Household size: 1 & 0 & & & & & & & & & \\
\hline Household size: 2 & $0.345^{*}$ & $(0.117)$ & $0.338^{*}$ & $(0.117)$ & $0.338^{*}$ & (0.118) & $0.334 *$ & (0.118) & $0.435^{*}$ & $(0.159)$ \\
\hline Household size: 3 or 4 & $1.056 *$ & (0.122) & $1.063^{*}$ & $(0.132)$ & $1.068 *$ & (0.123) & $1.087^{*}$ & $(0.129)$ & $1.196 *$ & $(0.170)$ \\
\hline Household size: >4 & $0.860^{*}$ & (0.219) & $0.930 *$ & $(0.217)$ & $0.864 *$ & $(0.224)$ & $0.952 *$ & $(0.222)$ & $2.072 *$ & $(0.311)$ \\
\hline Male & 0.285 & $(0.186)$ & 0.248 & $(0.198)$ & 0.271 & $(0.182)$ & 0.221 & $(0.192)$ & 0.141 & $(0.308)$ \\
\hline Occup: blue coll priv sector and other & 0 & & & & & & & & & \\
\hline Occup: white coll priv sector & $0.284^{*}$ & $(0.117)$ & $0.330^{*}$ & $(0.125)$ & $0.255^{*}$ & $(0.114)$ & $0.286^{*}$ & $(0.120)$ & 0.031 & $(0.152)$ \\
\hline Occup: self-employed & 0.116 & (0.123) & 0.202 & $(0.130)$ & 0.101 & $(0.123)$ & 0.173 & $(0.127)$ & -0.074 & (0.147) \\
\hline Occup: public sector & $0.365^{*}$ & $(0.125)$ & $0.388^{*}$ & $(0.130)$ & $0.337 *$ & $(0.124)$ & $0.350^{*}$ & $(0.128)$ & 0.241 & $(0.171)$ \\
\hline House age: before 1971 & 0 & & & & & & & & & \\
\hline House age: $1971-1980$ & $0.320 *$ & $(0.057)$ & $0.311^{*}$ & $(0.057)$ & $0.311 *$ & $(0.056)$ & $0.300 *$ & $(0.056)$ & 0.156 & $(0.103)$ \\
\hline House age: $1981-1990$ & $0.484^{*}$ & $(0.061)$ & $0.513^{*}$ & $(0.065)$ & $0.477^{*}$ & $(0.060)$ & $0.502 *$ & $(0.062)$ & $0.265^{*}$ & $(0.111)$ \\
\hline House age: $1991-2000$ & $0.566 *$ & $(0.068)$ & $0.530 *$ & $(0.072)$ & $0.571 *$ & $(0.068)$ & $0.535 *$ & $(0.073)$ & $0.552^{*}$ & $(0.124)$ \\
\hline House age: after 2000 & $1.055^{*}$ & $(0.077)$ & $1.026^{*}$ & $(0.087)$ & $1.066^{*}$ & $(0.081)$ & $1.037^{*}$ & $(0.093)$ & $0.751^{*}$ & (0.191) \\
\hline House size $<45 \mathrm{~m} 2$ & 0 & & & & & & & & & \\
\hline House size $45-64 \mathrm{~m} 2$ & $1.340^{*}$ & $(0.377)$ & $1.199 *$ & $(0.360)$ & $1.389 *$ & $(0.368)$ & $1.292 *$ & $(0.347)$ & -0.255 & $(0.502)$ \\
\hline House size $65-104 \mathrm{~m} 2$ & $1.675^{*}$ & $(0.362)$ & 1.593* & $(0.348)$ & $1.700^{*}$ & $(0.359)$ & $1.651^{*}$ & $(0.346)$ & -0.277 & $(0.450)$ \\
\hline House size $105-184 \mathrm{~m} 2$ & $2.281^{*}$ & $(0.358)$ & $2.155^{*}$ & $(0.343)$ & $2.309^{*}$ & $(0.356)$ & $2.218^{*}$ & $(0.342)$ & 0.237 & $(0.456)$ \\
\hline House size $>184 \mathrm{~m} 2$ & $2.456 *$ & $(0.364)$ & $2.356 *$ & $(0.347)$ & $2.479 *$ & $(0.364)$ & $2.415 *$ & $(0.348)$ & 0.375 & $(0.461)$ \\
\hline House type: detached & 0 & & & & & & & & & \\
\hline House type: semi-detached & $0.283^{*}$ & $(0.058)$ & $0.313^{*}$ & $(0.065)$ & $0.283^{*}$ & $(0.058)$ & $0.314^{*}$ & $(0.065)$ & $0.166^{*}$ & $(0.064)$ \\
\hline House type: terraced & 0.078 & $(0.057)$ & 0.067 & $(0.062)$ & 0.064 & $(0.058)$ & 0.049 & $(0.063)$ & 0.066 & (0.103) \\
\hline House type: apartment & $-0.542 *$ & $(0.066)$ & $-0.576 *$ & $(0.070)$ & $-0.526 *$ & (0.061) & $-0.549 *$ & $(0.062)$ & -0.072 & (0.124) \\
\hline Double glazing & $0.344 *$ & $(0.075)$ & $0.352 *$ & $(0.081)$ & $0.356^{*}$ & $(0.075)$ & $0.375^{*}$ & $(0.082)$ & $0.326^{*}$ & $(0.102)$ \\
\hline Roof insulation & $-0.441 *$ & $(0.070)$ & $-0.384 *$ & $(0.079)$ & $-0.449 *$ & $(0.068)$ & $-0.398 *$ & $(0.077)$ & $-0.374 *$ & $(0.126)$ \\
\hline Roof: good condition & $0.443^{*}$ & $(0.115)$ & $0.437^{*}$ & $(0.118)$ & $0.435^{*}$ & $(0.116)$ & $0.425^{*}$ & (0.119) & -0.067 & $(0.170)$ \\
\hline Alpha & & & $0.0310^{*}$ & $(0.002)$ & & & $0.0301 *$ & $(0.002)$ & & \\
\hline Observations & 8471 & & 8471 & & 8,471 & & 8,471 & & 8,471 & \\
\hline Loglikelihood & -27419 & & -26632 & & -27283 & & -26519 & & -26746 & \\
\hline
\end{tabular}

Notes: Results from maximum likelihood estimation with municipality fixed effects. Robust standard errors in parentheses, clustered by municipality. * indicates $p<0.05$. Dependent variable is total number of PV installations Notes: Results from maximum likelihood estimation with municipality fixed effects. Robust standard errors in parentheses, clustered by municipality. "indicates
at the end of 2012. Unless otherwise indicated, the explanatory variables are expressed as percentages. 0-values indicate the variable is reference category.

Table 6: Comparing different count models 


\section{APPENDIX B: RESULTS FROM MODEL WITHOUT URBAN AREAS}

Table 7: Excluding urban areas shows the results of the main model (3), excluding urban areas. The first column, repeats our main specification. The second column removes all 'big cities' $(9.79 \%$ of sectors or $19.51 \%$ of households). In the third column, we additionally remove 'regional cities' (6.68\% of sectors or $8.26 \%$ of households), while in the final column we also remove medium-sized cities (12.62\% of sectors or $10.88 \%$ of households). Overall, in the last column $29.09 \%$ of observations, or $38.65 \%$ of households are removed.

Despite the fact that a lot of observations are removed, results are very robust, both qualitatively and quantitatively. All significant parameters have the same signs and very similar values. A small number of parameters loses significance at the $5 \%$ level. This is the case for white collar and public sector occupations and houses of size $45-64 \mathrm{~m}^{2}$.

Furthermore, also the effect of the regressors in the second stage ('Left votes' and 'Subsidy') are very robust when we exclude urban areas. This is because we control for a large number of variables that explain the low adoption in urban municipalities, such as the negative effects of population density and the percentage of apartments. 


\begin{tabular}{|c|c|c|c|c|c|c|c|c|}
\hline \multirow{4}{*}{$\begin{array}{l}\text { VARIABLES } \\
\text { Households (log) } \\
\text { Income: average (log) }\end{array}$} & \multirow{2}{*}{\multicolumn{2}{|c|}{ (as in paper) }} & \multicolumn{4}{|c|}{ Model 3} & \multirow{2}{*}{\multicolumn{2}{|c|}{ + Excl. 14 medium-sized citie }} \\
\hline & & & & & + Ex & cities & & \\
\hline & $1.011^{*}$ & $(0.007)$ & $1.008^{*}$ & $(0.006)$ & $1.008^{*}$ & $(0.006)$ & $1.005^{*}$ & $(0.007)$ \\
\hline & 0.094 & $(0.061)$ & 0.016 & $(0.052)$ & 0.009 & $(0.056)$ & 0.011 & $(0.060)$ \\
\hline Income: dispersion (log) & $0.152^{*}$ & $(0.034)$ & $0.145^{*}$ & $(0.034)$ & $0.139 *$ & $(0.034)$ & $0.139 *$ & $(0.036)$ \\
\hline Subsidy (1000EUR) & $0.176^{*}$ & (0.058) & $0.166 *$ & $(0.055)$ & $0.167^{*}$ & $(0.057)$ & $0.186 *$ & $(0.060)$ \\
\hline House value: EUR500-EUR744 & 0.027 & $(0.070)$ & 0.070 & $(0.065)$ & 0.004 & $(0.066)$ & 0.027 & $(0.071)$ \\
\hline House value: EUR745-EUR999 & 0.001 & (0.063) & 0.036 & $(0.067)$ & -0.004 & $(0.071)$ & -0.008 & $(0.077)$ \\
\hline House value: EUR1000-EUR1499 & 0.127 & $(0.076)$ & 0.148 & $(0.079)$ & 0.072 & $(0.077)$ & 0.068 & $(0.086)$ \\
\hline House value: EUR1500-EUR2499 & $-0.269 *$ & (0.091) & $-0.220 *$ & $(0.092)$ & $-0.278^{*}$ & $(0.095)$ & $-0.261 *$ & $(0.100)$ \\
\hline House value: >EUR2500 & $-0.732 *$ & $(0.136)$ & $-0.693 *$ & $(0.137)$ & $-0.809 *$ & $(0.129)$ & $-0.807 *$ & $(0.134)$ \\
\hline Population density (log) & $-0.048^{*}$ & $(0.007)$ & $-0.039 *$ & $(0.005)$ & $-0.038 *$ & $(0.006)$ & $-0.039 *$ & $(0.006)$ \\
\hline Age: $25-34$ & 0.226 & $(0.435)$ & 0.315 & $(0.443)$ & 0.536 & $(0.471)$ & 0.590 & $(0.515)$ \\
\hline Age: $34-44$ & 0.318 & (0.404) & 0.593 & $(0.405)$ & 0.756 & $(0.440)$ & 0.875 & $(0.485)$ \\
\hline Age: $45-65$ & -0.454 & $(0.402)$ & -0.197 & $(0.412)$ & -0.060 & $(0.447)$ & 0.034 & $(0.488)$ \\
\hline Age: $>65$ & -0.735 & $(0.403)$ & -0.557 & $(0.416)$ & -0.393 & $(0.438)$ & -0.246 & $(0.474)$ \\
\hline Educ: High school & 0.133 & $(0.118)$ & 0.081 & $(0.118)$ & 0.098 & $(0.123)$ & 0.156 & $(0.134)$ \\
\hline Educ: College & 0.011 & $(0.106)$ & 0.046 & $(0.104)$ & 0.102 & $(0.100)$ & 0.160 & $(0.106)$ \\
\hline Foreigners & $-2.118^{*}$ & $(0.230)$ & $-1.927 *$ & (0.179) & $-1.734 *$ & $(0.147)$ & $-1.674 *$ & $(0.149)$ \\
\hline Left votes & 0.203 & $(0.140)$ & 0.232 & (0.139) & 0.231 & (0.137) & 0.266 & $(0.141)$ \\
\hline Environmental awareness & $1.172^{*}$ & $(0.161)$ & $1.013^{*}$ & $(0.156)$ & $0.912^{*}$ & $(0.165)$ & $1.041^{*}$ & $(0.183)$ \\
\hline House owner & $0.383^{*}$ & $(0.068)$ & $0.388^{*}$ & $(0.071)$ & $0.413^{*}$ & $(0.072)$ & $0.398 *$ & $(0.075)$ \\
\hline Household size: 2 & $0.345^{*}$ & $(0.117)$ & $0.294 *$ & $(0.121)$ & $0.298 *$ & $(0.128)$ & $0.309 *$ & $(0.142)$ \\
\hline Household size: 3 or 4 & $1.056^{*}$ & $(0.122)$ & $1.047^{*}$ & (0.129) & $1.067^{*}$ & $(0.134)$ & $1.048 *$ & $(0.147)$ \\
\hline Household size: $>4$ & $0.860^{*}$ & $(0.219)$ & $0.902 *$ & $(0.233)$ & $1.068^{*}$ & $(0.238)$ & $1.114^{*}$ & $(0.265)$ \\
\hline Male & 0.285 & $(0.186)$ & 0.207 & $(0.176)$ & 0.226 & $(0.186)$ & 0.208 & $(0.200)$ \\
\hline Occup: white coll priv sector & $0.284 *$ & $(0.117)$ & 0.161 & $(0.104)$ & 0.137 & $(0.108)$ & 0.107 & $(0.116)$ \\
\hline Occup: self-employed & 0.116 & $(0.123)$ & 0.066 & $(0.118)$ & 0.020 & $(0.116)$ & 0.012 & $(0.128)$ \\
\hline Occup: public sector & $0.365 *$ & $(0.124)$ & $0.301 *$ & $(0.118)$ & 0.213 & $(0.116)$ & 0.201 & $(0.117)$ \\
\hline House age: $1971-1980$ & $0.320^{*}$ & $(0.057)$ & $0.284 *$ & $(0.059)$ & $0.312^{*}$ & $(0.062)$ & $0.335^{*}$ & $(0.068)$ \\
\hline House age: $1981-1990$ & $0.484 *$ & $(0.061)$ & $0.465^{*}$ & $(0.059)$ & $0.465^{*}$ & $(0.060)$ & $0.500^{*}$ & $(0.068)$ \\
\hline House age: $1991-2000$ & $0.566 *$ & $(0.068)$ & $0.516 *$ & (0.071) & $0.515^{*}$ & $(0.074)$ & $0.505^{*}$ & $(0.079)$ \\
\hline House age: after 2000 & $1.055^{*}$ & $(0.077)$ & $1.033^{*}$ & $(0.079)$ & $1.010 *$ & $(0.081)$ & $1.015^{*}$ & $(0.090)$ \\
\hline House size $45-64 \mathrm{~m} 2$ & $1.340^{*}$ & $(0.377)$ & $0.901 *$ & $(0.408)$ & 0.924 & $(0.494)$ & 0.996 & $(0.591)$ \\
\hline House size $65-104 \mathrm{~m} 2$ & $1.675^{*}$ & $(0.362)$ & $1.300^{*}$ & $(0.359)$ & $1.387^{*}$ & $(0.453)$ & $1.398^{*}$ & $(0.559)$ \\
\hline House size $105-184 \mathrm{~m} 2$ & $2.281^{*}$ & $(0.357)$ & $1.946 *$ & $(0.366)$ & $1.993^{*}$ & $(0.456)$ & $2.009 *$ & $(0.561)$ \\
\hline House size $>184 \mathrm{~m} 2$ & $2.456 *$ & $(0.364)$ & $2.121 *$ & $(0.365)$ & $2.177^{*}$ & $(0.455)$ & $2.142 *$ & $(0.561)$ \\
\hline House type: semi-detached & $0.283^{*}$ & $(0.058)$ & $0.230 *$ & $(0.048)$ & $0.205 *$ & $(0.043)$ & $0.193 *$ & $(0.048)$ \\
\hline House type: terraced & 0.078 & $(0.057)$ & 0.016 & $(0.058)$ & -0.009 & $(0.062)$ & 0.030 & $(0.068)$ \\
\hline House type: apartment & $-0.542 *$ & $(0.066)$ & $-0.556^{*}$ & $(0.063)$ & $-0.562^{*}$ & $(0.065)$ & $-0.540 *$ & $(0.071)$ \\
\hline Double glazing & $0.344^{*}$ & $(0.075)$ & $0.332^{*}$ & $(0.074)$ & $0.376^{*}$ & $(0.078)$ & $0.378^{*}$ & $(0.086)$ \\
\hline Roof insulation & $-0.441 *$ & $(0.070)$ & $-0.431 *$ & $(0.070)$ & $-0.410^{*}$ & $(0.072)$ & $-0.452^{*}$ & $(0.078)$ \\
\hline Roof: good condition & $0.443^{*}$ & $(0.115)$ & $0.475 *$ & (0.119) & $0.460 *$ & $(0.123)$ & $0.441^{*}$ & $(0.132)$ \\
\hline Constant & $-8.480 *$ & $(0.807)$ & $-7.297 *$ & (0.697) & $-7.336 *$ & $(0.767)$ & $-7.542 *$ & $(0.855)$ \\
\hline Observations & 8471 & & 7682 & & 7107 & & 6028 & \\
\hline Loglikelihood 1st stage & -27419 & & -24714 & & -22815 & & -19528 & \\
\hline $\mathrm{R}^{2}$ 2nd stage & 0.0360 & & 0.0389 & & 0.0404 & & 0.0484 & \\
\hline
\end{tabular}

Notes: Results from GMM estimation of Poisson model as discussed in the text. Robust standard errors

Table 7: Excluding urban areas 


\section{APPENDIX C: CALCULATION OF NET PRESENT VALUE}

In section 2 we explained that the fundamental incentives that drive the decision to invest in PVs are the upfront installation costs and the future benefits from electricity production. We then discussed how the government can influence both components through subsidies and tax cuts. In this Appendix we provide some simplified calculations on the relative importance of the various cost and benefit components in present value terms.

One can distinguish between the following main components: (1) the upfront investment cost, (2) the investment subsidies, (3) the future benefits from electricity expenditure savings, (4) the future benefits from TGC subsidies. We calculate these components for a typical PV system with a capacity of $5 \mathrm{~kW}$. To convert future benefits in net present value terms, we use an interest rate of $15 \%$, which government agencies have often used in the calculation of the required subsidy levels.

To compute the upfront investment price, we collected price data on solar panel in Flanders using two sources: an internet forum with consumers' reported price offers (zonstraal.be) and a website with historical data (comparemysolar.be). This resulted in a dataset of 2659 quotes from May 2009 - December 2012 for the total investment cost of PVs between 0 and $10 \mathrm{~kW}$. We then calculated the average price per $\mathrm{kW}$ for consecutive half year periods, to come up with the cost of a typical 5kW PV system, assuming a VAT rate of $6 \%$.

The investment subsidies consist of benefits from tax cuts (spread over at most the first four years after installation) and the subsidies granted by the municipalities.

To compute the future benefits from electricity expenditure savings through net metering, we make assumptions similar to those made by the federal energy regulator CREG: a 5kW system produces $4.25 \mathrm{MWh}$ per year and has a lifetime of 20 years. We use Eurostat data on electricity prices, assuming future electricity prices are expected to rise by $7 \%$ annually (as was the actual trend during 2006 and 2012).

To compute the future benefits from the TGC subsidies on electricity production, we again consider a 5kW system producing 4.25 MWh per year with subsidy benefits of 20 years or less, depending on the time period.

Table 7 shows the net present value for each of the four components.

(1) The investment price was approximately $22,400 €$ in the second half of 2009 and dropped to $10,400 €$ in the second half of 2012.

(2) Investment subsidies were $40 \%$ before 2012 and thus approximately $8,900 €$ in 2009 and dropped to 0 in 2012.

(3) The net present value of electricity expenditure savings remained relatively stable between 8,800 and $10,000 €$.

(4) The net present value of from the TGC subsidies on future electricity production was initially by far the most important source of subsidies, but it dropped to a small amount near the end of the period.

\begin{tabular}{|c|c|c|c|c|}
\hline TIME PERIOD & $\begin{array}{c}\text { Investment cost } \\
\text { (1) }\end{array}$ & $\begin{array}{c}\text { Investment } \\
\text { subsidies } \\
\text { (national level) } \\
\text { (2) }\end{array}$ & $\begin{array}{c}\text { Net present value } \\
\text { electricity } \\
\text { expenditure } \\
\text { savings (3) }\end{array}$ & $\begin{array}{c}\text { Net present value } \\
\text { subsidies from } \\
\text { green certificates } \\
\text { (4) }\end{array}$ \\
\hline 2009 & 22,446 & 8,978 & 8,799 & 13,302 \\
\hline 2010 & 17,420 & 6,968 & 9,440 & 10,346 \\
\hline 2011 & 15,379 & 6,152 & 9,802 & 8,425 \\
\hline 2012 & 10,371 & 0 & 10,184 & 2,785 \\
\hline
\end{tabular}

Notes: net present values calculated at a rate of $15 \%$. Values are calculated at the end of each year (average over the last 6 months)

Table 8: net present value of PV. 